
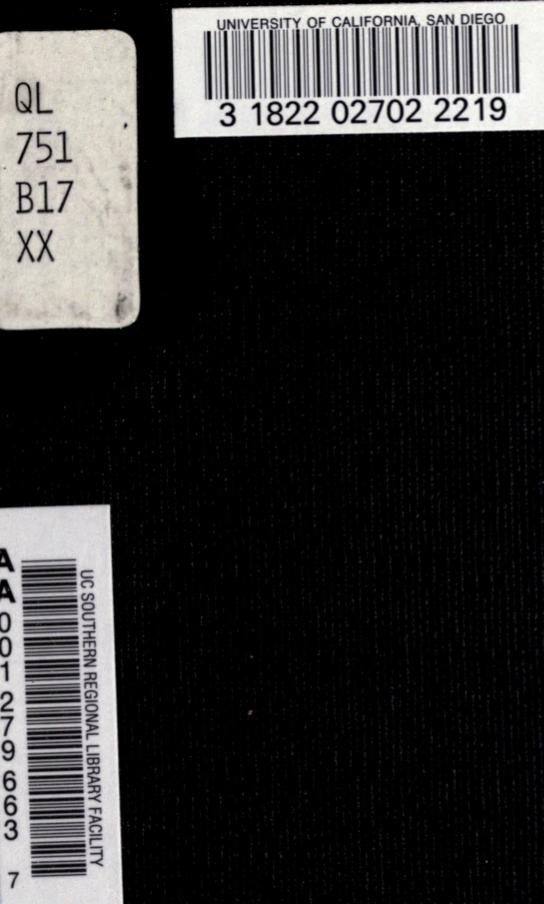
LIBRARY UNIVERSITY OF
CALIFORNIA SAN DIEGO 


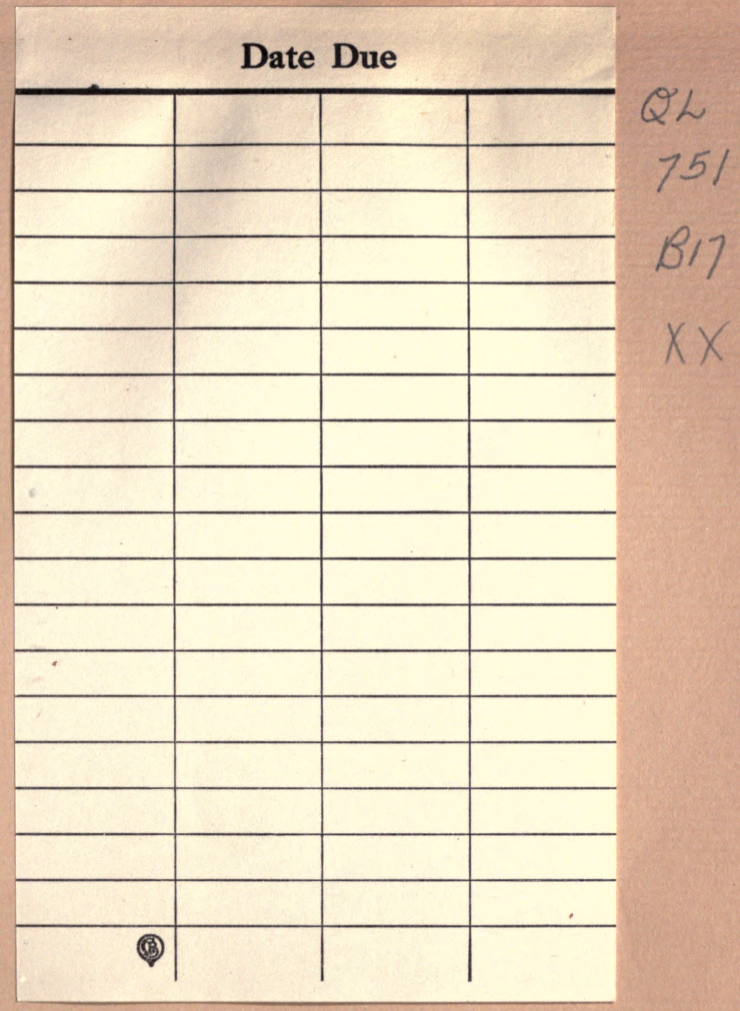




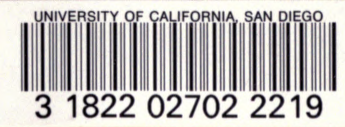




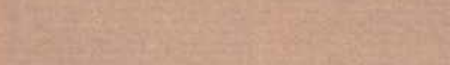




\title{
INDIVIDUAL DIFFERENCES AND FAMILY RESEMBLANCES IN ANIMAL BEHAVIOR
}

\begin{abstract}
A STUDY OF HABIT FORMATION IN VARIOUS STRAINS OF MICE
\end{abstract}

BY

HALSEY J. BAGG

ARCHIVES OF PSYCHOLOGY

BDITED BX

R. S. WOODWORTH

NO. 43, JUNE, 1920

Coldmain Univergity Contributiong to Philogophy and Paxchologx

VoruMr XXVI, No. 4

NEW YORK

THE SCIENCE PRESS

AGENTs: G. E. STECHERT \& CO.; London (2 r Yard, Carey S W. C.); Leipaig (Koenigatr., 37;

Paris (I6 
PRESS OF
THE NEW ERA PRINTING COMPANY LANCASTER, PA.

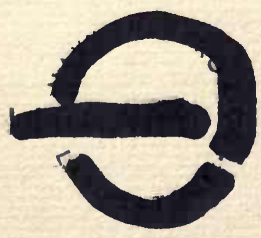




\section{ACKNOWLEDGMENTS}

THE writer is indebted, above all, to Professor J. McKeen Cattell for suggesting the problem, and for helpful criticism and encouragement throughout the experiment. In the preparation of the manuscript, and in the evaluation of the statistical material, thanks are also due to Professors Robert S. Woodworth, Edward L. Thorndike and Henry A. Ruger. 



\section{CONTENTS}

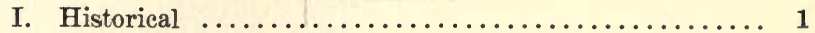

II. Statement of the Problem .................. 3

III. Methods of the Experiment................ 4

IV. Tests of Learning Ability.................. 6

(a) In the Maze.......................... 6

(b) In the Multiple Choice Apparatus........... 6

V. Experimental Results ................... 9

(a) Time and Error Averages for all Tests......... 9

(b) Difference in Learning between Families of White and Yellow Mice.................... 9

(c) Results for Maze Test................... 11

(1) The Initial Learning................. 11

(2) The Interference $\ldots \ldots \ldots \ldots \ldots \ldots \ldots \ldots \ldots$

(3) The Retention .................... 18

(d) Results for Multiple Choice Test............ 20

VI. Correlations in Learning Records between:

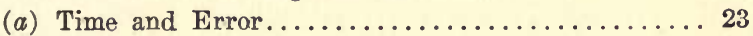

(b) Performance at Beginning and End of Tests...... 24

(c) Initial Learning Records and Retention......... 24

(d) Performance in Maze Test with Performance in Multiple Choice Test .................... 25

VII. Family Resemblances ................... 26

Mean Variations for Related and Unrelated Individuals. . 27

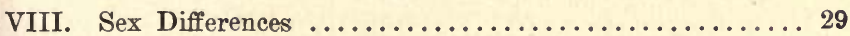

(a) Differences in Time and Error Records......... 29

(b) Comparative Distributions of the Males and Females. 30

(c) Variability of the Sexes....................33

IX. Individual Differences and Methods of Habit Formation.. 35

X. Health Conditions and Learning Ability........... 42

XI. Family Histories ...................... 44

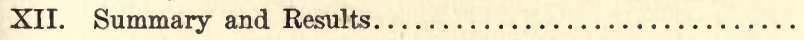




\section{HISTORICAL}

In the present thesis an effort has been made to combine in a single study three main points of investigation; first, the genetic study of behavior; secondly, the subject of individual differences; and thirdly, a consideration of the exact method of habit formation employed by the mice that have been tested in the experiments that are now to be reported.

Practically no experimental work has been done upon individual differences and family resemblances in animal behavior. In most cases, the behaviorist has been content to study the mass reaction of a group of animals to external stimuli, and in the main, has not attempted to treat the variability of his group because of the relatively small number of animals tested. Professor J. McKeen Cattell, about fifteen years ago, began to apply the methods of genetics to the study of conduct, but the results obtained by him and his students were not published, and the problem has been given to me. Yerkes devotes a chapter of his book on "The Dancing Mouse,"1 to differences in behavior, and there brings together results for variability in ". . . general behavior, rapidity of learming, memory, and discrimination." His results showed the existence of a considerable amount of individual differences in the behavior of the dancing mouse, and no family resemblance in the litters he obtained. He does not give quantitative results, but confines himself to a general discussion of the individual peculiarities of the animals he had tested. The following quotation from his text expresses this point: "I noted, in this test of the animals' ability to learn, that while one individual would be scurrying about trying all ways of escape, investigating its surroundings, looking, sniffing, and dancing by turns, another would devote all its time to whirling, circling, or washing itself. One in the course of its activity would happen upon the way of escape, the other by reason of the limited scope of its activity, not the lack of it, would fail hour after hour to discover even the simplest way of getting back to its nest, to food, and to its companions." Concerning the "inheritance of forms of behavior," Yerkes found that certain lines of descent exhibited a pronounced tendency to whirl to the left, while others reacted in the opposite direction. When two such strains were crossed the offspring showed an equal frequency of left and

1 Yerkes, Chapter 17, "The Dancing Mouse." 
right whirlers. It was also found that there was no "inheritance of individually acquired forms of behavior." Apparently the descendants of animals that had been previously trained to learn a certain task were given no advantage over ordinary individuals from untrained stock.

G. V. Hamilton in his monograph entitled "A Study of Perseverance Reactions in Primates and Rodents," "2 found that there were definite types of behavior exhibited by the various subjects he used. These consisted of twenty children, a baboon, four monkeys, and five kinds of rodents, comprising, one mouse, five gray rats, five black rats, ten white rats and six gophers. The reactions of the monkeys and the baboon presented a considerable range of individual differences, which determined the experimenter in the selection of his subjects, as indicated in the following quotation: "The marked individual differences presented by the five infra-human primate subjects reflect a policy of selecting subjects in whom oddities of general reactive equipment had been observed." Later on in the investigation the author refers to the presence of individual differences, as follows: "When a mammalian is confronted by a series of situations for which he is unable to discover and stereotype a specifically adequate and invariably successful mode of response he tends to vary his response in a manner which is less a species than an individual characteristic."

The writer has had the opportunity of going over the original data of Basset's work on white rats, ${ }^{3}$ and finds that a certain amount of individual difference occurs in the animals he tested. Some animals did consistently better work than others, but as Basset himself points out, his numbers were too few to make possible any conclusions from the differences that were observed.

One might mention a large number of isolated eases where the literature of comparative psychology gives evidence of individual differences. It would not be worth while to treat them here, however, because they generally deal with relatively few animals, and are given merely as side issues of experiments planned to bring out other factors.

2 Hamilton, "A Study of Perseverence Reactions in Primates and Rodents," Behavior Monograph Series, No. 13, 1916.

3 Basset, "Habit Formation in a Strain of White Rats with Less than Normal Brain Weight," Behavior Monograph Series, No. 9, 1914. 


\section{STATEMENT OF THE PROBLEM}

THE plan of the experimental work presented in this investigation is to measure individual differences in behavior, to determine the extent to which the animal that departs from the average in one direction will depart in others, to measure the resemblances in families and in lines of descent, and to determine whether kinds of conduct can be established in family lines by selection. In a previous publication, ${ }^{4}$ of which this thesis is a continuation, it was found that individual differences occurred in the ability of various strains of mice to learn a simple maze, and also that a family resemblance existed among mice of the same litter, that amounted to a coefficient of correlation in the neighborhood of 0.50. Certain mice, and even whole lines of descent, showed marked variations from the average, some taking more than twice the average time to learn a given task. These differences were well beyond the limits of the probable error. The results were obtained from testing 90 mice, as determined by the time required to find their way through a maze. Since then, these mice and their offspring have been tested in other ways, and further experiments are now in progress with the $\mathrm{F}^{7}$ and $\mathrm{F}^{8}$ generations. In the present investigation there are described the individual differences and family resemblances of 93 mice, in addition to the 90 already reported on in the previous article. These mice have been tested in the same maze as were the previous ones; in addition, they have been given an interference test, a retention test and have been studied in a second maze, as deseribed below.

4 Bagg, "Individual Differences and Family Resemblances in Animal Behavior," The American Naturalist, April, 1916.

The present material was submitted for publication in June, 1918. 


\section{METHODS OF THE EXPERIMENT}

THE first maze employed was designed by Professor Cattell, the plan of which is shown in Fig. 1. The animal has, in the first compartment, the alternative between two gates, one of which can be pushed open, while the other is locked, with an identical situation in a second compartment. The path that the animal must follow can be altered by varying the position of the open gates. "Unit construction" is used in the dimensions, which are adjusted to the size of the animals used, and which permit the addition of any desired number of standard units.

Preliminary tests were made with albino rats, but later mice, which are more active and more easily handled, were substituted. The mice were given one trial each day at as nearly the same time as possible. Light was found to play but a minor rôle in the tests, daylight and artificial light serving equally well. At the outset the age of the mice when first tested was not always known, but later, when the various litters were obtained, the young mice were tested at, or about, the age of four weeks.

The mice were rewarded for a successful trial by a mixed diet of milk, bread, oatmeal and sometimes meat. A little dry bread was always in their cages. Besides satisfying their hunger, the mice had the additional reward of a place to exercise and the companionship of the mice that had just been tested. The order of the tests was varied day by day. In case the way through the maze was not found in 360 seconds the animal was removed and tested again the follow. ing day. The maximum record for a single trial is 360 seconds. 


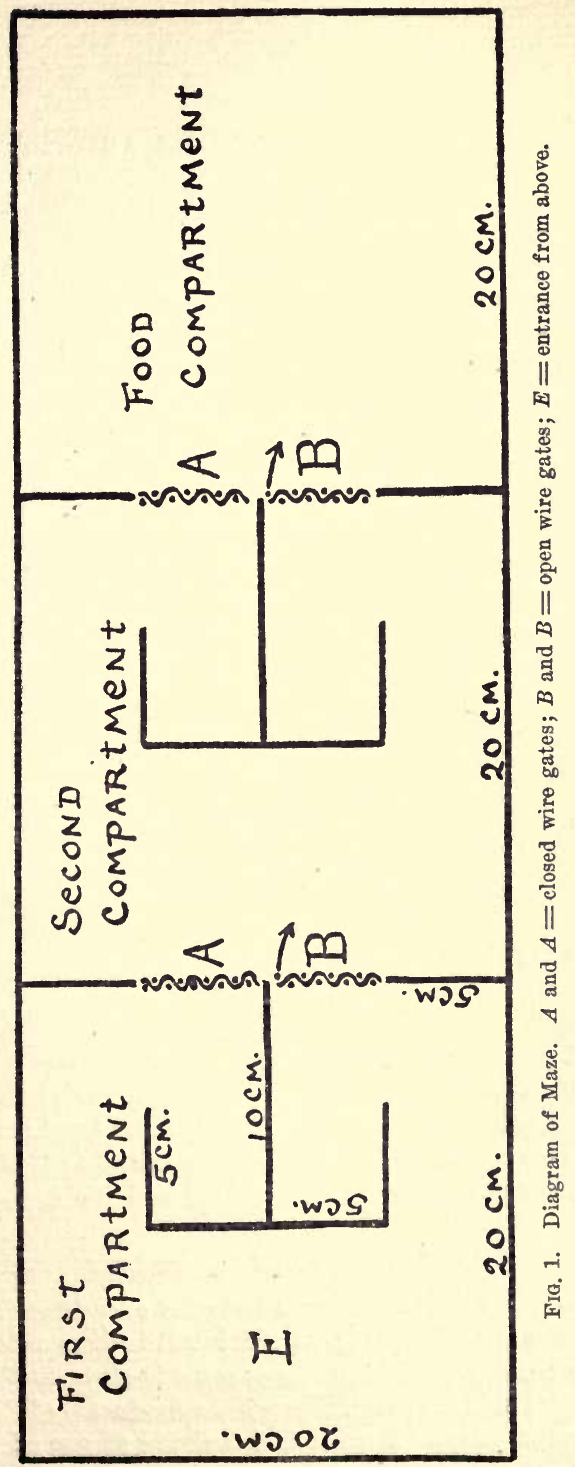




\section{TESTS OF LEARNING ABILITY}

\section{(a) The Maze Test}

IN the maze test, the mice were first given an initial learning test of seventeen trials. This was a desirable number for two reasons; first, because it was sufficient for the average mouse to learn the maze, and secondly, because the seventeen trials could be divided into three groups representing comparatively distinct stages in the course of learning. The first stage includes the first two trials which are largely affected by chance, and although given here for completeness, are not averaged in the final ratings for each individual. The second group, including the next five trials, represents a period of continued rapid, but less variable learning; the third group, including the following ten trials, covers the period of slow or nearly completed learning. The first group of 90 mice was given only this initial learning test of seventeen trials. The behavior of the latter group of 93 mice was more completely studied. After the seventeen trials the gates were changed, so that the ones that had been open were locked, and those closed were open. This was an interference test designed to give a measure of the adaptability of the animals. It was necessary for the mouse to break the old habit, and learn to get through the maze by way of the previously closed gates. In the first trial after this change, the interference effects were pronounced, although in the eleven subsequent trials the mice rapidly learned the new order. The interference test was divided into two groups. The first two trials were put in one group, and the remaining ten trials in a second group. The first group of two trials gives a measure of the direct effect of the interference upon the animal's behavior, while the second group of ten trials shows the degree to which this interference is carried over into the following trials, and, in a fashion, indicates the adaptability of each animal and the flexibility of its behavior.

\section{(b) The Multiple Choice Test}

Upon finishing the interference tests the mice were immediately started upon a second experiment which will be here called the multiple choice test. A plan of the apparatus is given in Fig. 2. The mouse was placed in the maze, through the door marked " $E$," within the first compartment. Here it had a choice of one of four gates, 
marked in the diagram 1, 2, 3, 4. Three of these gates are blue and one is red. ${ }^{5}$ Punishment was given at the blue gates, but not at the red. The gates are the same size as those used in the maze test just

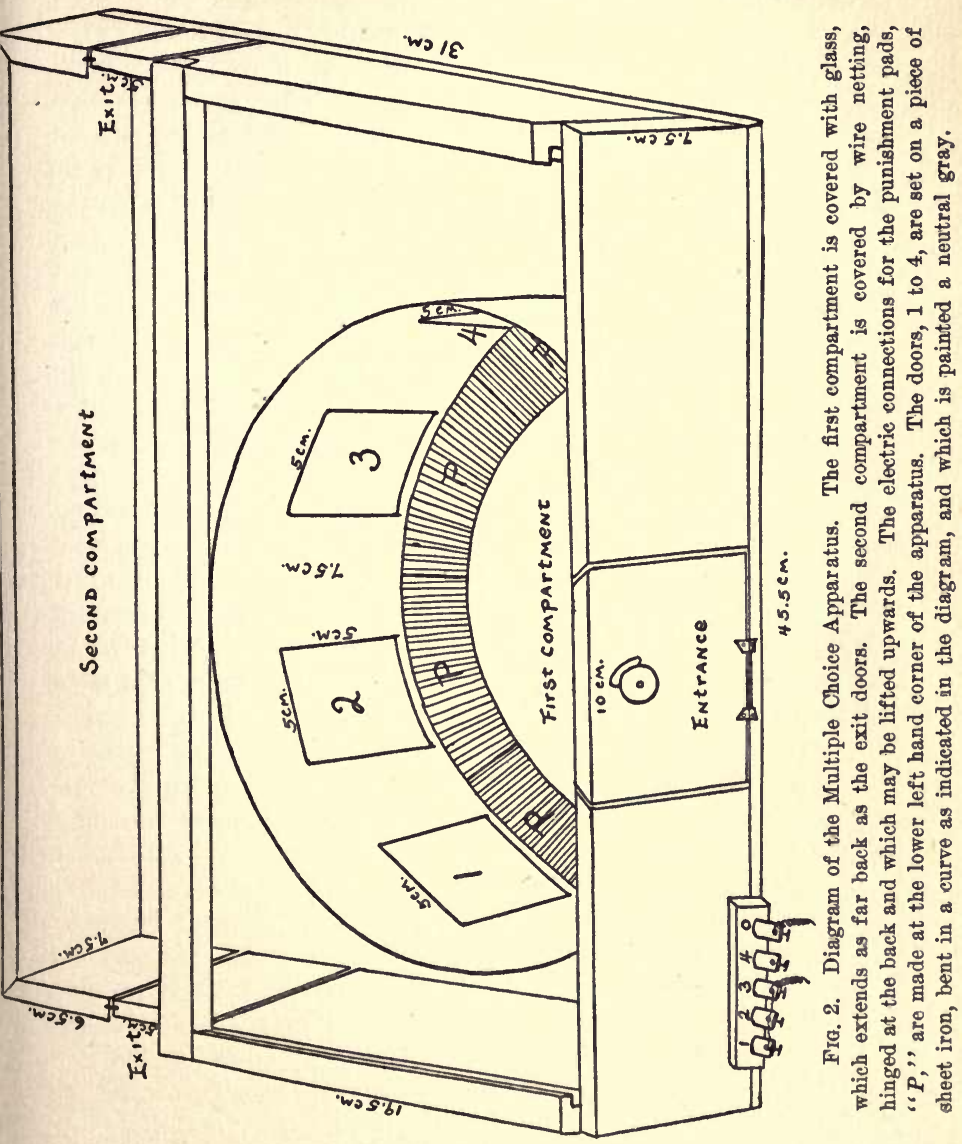

5 The Milton Bradly papers, red and blue were used, and, in so far as the experiment was not designed to test the color sense of the animals, the brightness value of the colors was not determined. The papers were changed from time to time, but the odor factors were not eliminated. These clews, if they existed as such, for the animals, were purposely retained, and the mice were allowed to make use of them in solving their problems. 
described, the red one being the only one which could be pushed open, and through it the mouse could enter the second compartment. If the mouse attempted to pass through one of the blue doors it received a slight electric shock from the punishment pad "P," which was on the floor of the maze directly in front of the door. The position of the red gate was changed every day, being now in one place and now in another, following a program which had previously been made out. After making the successful choice, the mouse entered the second compartment where he was free to go directly into its nest cage by means of one of the exit doors, where the usual reward was given. Twenty-five trials were made with each individual, and, as in the previous maze, the trials were divided into three somewhat homogeneous groups. The first group, irregular on account of the great play of chance, includes the first two trials; the second group, including the next five trials, marks the period of rapid learning, and the third group of eighteen trials represents the period when the learning was practically completed. It has been found, as will be discussed later on, that the last period of trials was longer than necessary; in fact, the mice showed very little improvement during this period. The day after completing the trials in the multiple choice test the animals were given a series of trials in the maze test first considered. This was a retention test, designed to give a measure of the permanence of association for the previously learned task. In this case ten trials were given, and the gates were opened in the same order as during the last ten trials of the interference test. 


\section{EXPERIMENTAL RESULTS}

\section{(a) Time and Error Averages for All Tests}

Tables I. to VII. give the time and the number of errors, i.e., the number of cases in which the mouse tried to go through a locked gate, which is a measure of the activity of the animal. In this paper the average of the last fifteen trials is used as an index of perform. ance for the first set of seventeen trials in the maze test, and the last 23 trials are used as an index for the 25 trials in the multiple choice test, in each ease the first two trials being eliminated for irregularities previously mentioned. The groups of two and ten trials each in the interference test, and the group of ten in the retention test are used as indexes for the respective cases. The above tables give the complete records of the 183 mice tested, grouped in families as described below. The average time is $54.12 \pm$ P.E. 2.3 seconds per trial for the last fifteen trials in the maze test; $60.26 \pm$ P.E. 4.7 seconds for the last ten trials of the interference test; $52.81 \pm$ P.E. 4.7 seconds for the retention test, and $39.47 \pm$ P.E. .08 seconds for the last 23 trials of the multiple choice test. The distributions of the individuals in both experiments is shown in Fig. $3 .^{6}$ The distribution for the animals in the maze test, based on the average speed attained in the last fifteen trials is indicated by the solid line, and the distribution for those in the multiple choice test, based on the speed attained in the last 23 trials, by the broken line. In the maze test 65 animals took less than 20 seconds, in 47 cases the time was between 20 and 40 seconds, and there were 71 cases between 40 and 360 seconds. But one mouse failed to learn the maze. The distribution in the multiple choice test gave 30 eases in which the time was under 20 seconds, 20 cases between 20 and 40 seconds, and 26 cases between 40 and 280 seconds. None of the mice failed to learn the multiple choice test.

\section{(b) Difference in Learning between Famiutes of White and YeLLOW MICE}

As reported in the preliminary account of this experiment, it was found that certain strains of mice took considerably longer time to learn the maze than others tested at the same time. Among the

- Seventy-six of the 183 cases were tested in both the mazes given in these distributions. 
colored mice then tested, several yellow ones made poor records. These mice were mated, and they and their offspring compose a group of 27 individuals, whose average time and error record is con-

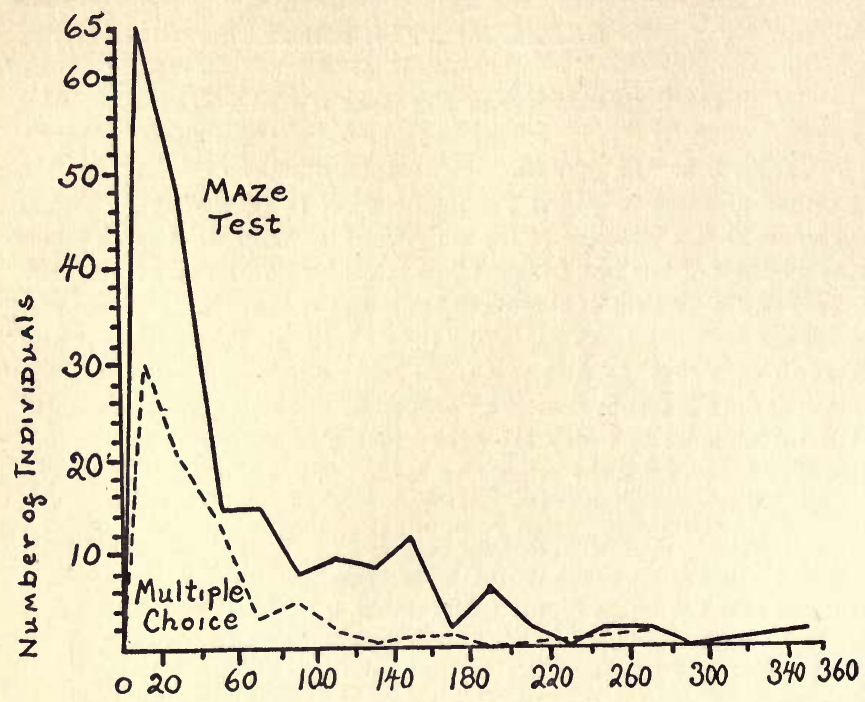

\section{Number of Seconds}

Fig. 3. Total Distribution Curves for Maze Test and Multiple Choice Test.

siderably poorer than the normal for the entire population. ${ }^{7}$ The yellow group gave an average time of $83 \pm$ P.E. 7.0 seconds, and an average of 2.0 errors for the last 15 trials. The remaining group of 63 mice, mostly white, gave an average time of $27.5 \pm$ P.E. 2 seconds and .9 error per trial. The yellow mice were thus found to take, on the average, at least three times as much time, and to make twice as many errors as did the white mice. The distribution curves for the white group is skewed, most of the individuals falling between 0 and 20 seconds. The curve for the yellow family is nearly flat, there being about the same number of individuals between 0 and 20 seconds, as between 60 and 80 seconds, and between 140 and 160 seconds.

7 This group of 27 mice was composed (see Tables I, IV and VII) of Nos. 20 and 26, and their seven offspring; No. 27, the sister of No. 26; a litter of five mice, Nos. 32, 33, 34, 36 and 37 and their ten offspring, and finally two unrelated yellow mice, Nos. 2 and 3, that were used at the beginning of the experiment. The 63 remaining mice of the white group bring the total to 90 . 
TABLE I

Complete Time and Error Records for the Yetow Family in the Maze Test

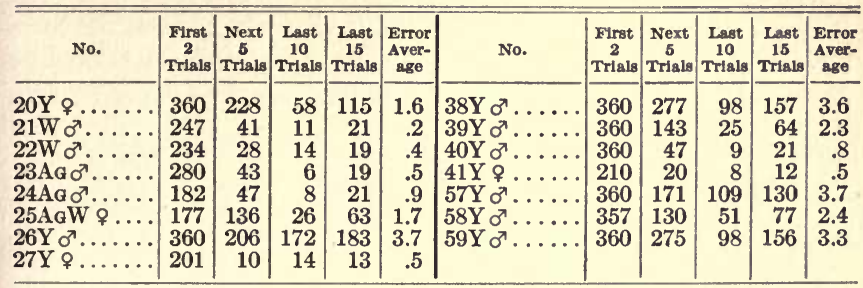

In the first column is given the catalogue number, color and sex of the animals. In the second are the time averages (in seconds) for the first two trials; in the third, for the next five trials; in the fourth, the last ten trials, and in the fifth column the average of the two preceding columns. The error average for the last 15 trials is given in the last row of figures. This order is followed in all the subsequent tables, but in Tables III and VI averages are added for the last group of five trials, and in addition these tables give the time and error averages for two interference tests of two and ten trials respectively; a retention test of ten trials, and finally the averages for the multiple choice test of 23 trials, which is divided, first, into a group of the two first trials, next the following five trials, next the last 18 trials, next the last 23 trials, next the last five trials, and finally the error averages for the last 23 trials.

One day's record has been omitted for mice Nos. 27, 28, 29 and 31 because the poor records for that day were obviously due to a constant error, on account of traveling, etc. These are the only cases where such a condition has occurred.

\section{(c) Results for the Maze Test}

Fig. 4 gives the complete record curves for all the tests given in the maze, showing curves based upon the average and the median record for each day, and, as indicated in the drawing, these may be divided into three main parts: first, an initial learning period of seventeen trials, second, the interference groups, consisting of two and ten trials, and finally a retention test of ten trials. 183 mice were tested in the first group of seventeen trials, and 71 in each of the succeeding groups. ${ }^{8}$ Two daily record curves were calculated for teach test, and in the upper curve (represented in the figure by a solid line and marked "average") the records for all the individuals in each group were averaged for each successive trial, and the

8 The tests that followed the initial learning period of seventeen trials were not instigated until the experiment was well started and the writer had become familiar with the peculiarities of the behavior of his subjects. Some animals died during the rather long period in which they were observed, and their incomplete records, although given in the tables, are not averaged in Fig. 4. 
probable error calculated for each point in the curve. In accordance with a plan proposed by Professor Cattell, the limits of the probable error are shown by the broken lines. The chances are even that with a greatly increased number of cases the time would have remained between these limits, and a nearly smooth curve can be drawn within them. When the gates were changed at the eighteenth

TABLE II

Complete Records for the White Family in the Maze Test

\begin{tabular}{|c|c|c|c|c|c|c|c|c|c|c|c|}
\hline No. & $\begin{array}{l}\text { First } \\
2 \\
\text { Trials }\end{array}$ & $\begin{array}{c}\text { Next } \\
5 \\
\text { Trials }\end{array}$ & $\begin{array}{c}\text { Last } \\
10 \\
\text { Trials }\end{array}$ & $\begin{array}{l}\text { Last } \\
15 \\
\text { Trials }\end{array}$ & \begin{tabular}{|l} 
Error \\
Aver- \\
gge
\end{tabular} & No. & $\begin{array}{l}\text { First } \\
2 \\
\text { Trials }\end{array}$ & $\begin{array}{c}\text { Next } \\
5 \\
\text { Trials }\end{array}$ & $\begin{array}{c}\text { Last } \\
10 \\
\text { Trials }\end{array}$ & $\begin{array}{c}\text { Last } \\
15 \\
\text { Trials }\end{array}$ & $\begin{array}{l}\text { Error } \\
\text { Aver- } \\
\text { age }\end{array}$ \\
\hline & & 91 & 56 & 67 & 1.9 & $33 \mathrm{~W}$ & 108 & 5 & 10 & 8 & \\
\hline & & 159 & 37 & 91 & 1.4 & & & 12 & 13 & 12 & 1.0 \\
\hline & 31 & 26 & 17 & 21 & .4 & $5 \mathrm{~W} \%$ & 99 & 12 & 11 & 11 & .8 \\
\hline & & 16 & 7 & 10 & .5 & & 284 & 22 & 12 & 15 & .9 \\
\hline & 18 & 75 & 25 & 42 & 1.9 & W & 101 & 69 & & 28 & .9 \\
\hline & 24 & 25 & 18 & 20 & .7 & & 93 & & & 8 & .4 \\
\hline & 5 & 13 & 7 & 9 & .5 & 11 & 67 & 13 & 12 & 12 & 1.0 \\
\hline & 16 & 12 & 10 & 11 & .9 & & 151 & 33 & 8 & 16 & .9 \\
\hline 0 & 19 & 77 & 34 & 48 & 1.7 & & 88 & 11 & 7 & 8 & .7 \\
\hline & 28 & 87 & 8 & 35 & 9 & & 75 & 13 & 5 & 8 & \\
\hline & 36 & 306 & 17 & 113 & 1.2 & & 70 & 13 & 11 & 12 & 1.0 \\
\hline & 36 & 173 & 25 & 75 & 1.7 & & 183 & 13 & 8 & 10 & .7 \\
\hline & & & 1 & & .9 & & & 11 & 4 & 7 & \\
\hline & 31 & 162 & 20 & 68 & 1.0 & & 81 & 14 & 10 & 12 & 1.0 \\
\hline & & & 91 & 122 & 2.9 & & & 40 & 9 & 20 & 1.1 \\
\hline & 14 & 12 & 1 & & .9 & & 118 & 19 & 7 & 11 & \\
\hline & 36 & 30 & 3 & 121 & 1.7 & & 64 & 17 & 9 & 12 & .0 \\
\hline & 8 & 29 & 2 & 24 & 1.2 & & 76 & 84 & 7 & 33 & \\
\hline & 8 & 19 & 1 & 1 & 1.2 & & 66 & 39 & 29 & 32 & 2.2 \\
\hline & 5 & 16 & 14 & 15 & 1.2 & & 25 & 23 & 10 & 14 & .9 \\
\hline & 86 & 14 & $\pi$ & 9 & .8 & & 189 & 15 & 7 & 9 & .0 \\
\hline & 110 & 16 & 10 & 12 & .9 & & 90 & 19 & 9 & 12 & 1.0 \\
\hline $91 \mathrm{~W}$ & 252 & 47 & 33 & 38 & 1.6 & & 72 & 22 & 11 & 15 & .9 \\
\hline
\end{tabular}

trial, an interference effect occurred that resulted in a rise of the time curve to 118 seconds at the first trial. This was just half the number of seconds it took the average mouse to go through the maze for the first time. The rest of the interference test showed an average time curve that was above the curve for the last few trials of the initial learning test, except for the sixth day of the interference test when the curve dropped to 40 seconds. The curve based on the average for the interference test began to follow the usual course of learning until the sixth day when the maximum speed record was reached, but at that point, for some unknown reason, a retarding factor occurred that caused a decided rise in the curve from then to the end of the test. There are two possible explanations for this phenomenon; first, that at the lowest point of the curve the mice had reached their maximum speed and efficiency and thereafter they 


\begin{tabular}{|c|c|c|}
\hline & 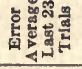 & ल \\
\hline \multirow{5}{*}{ 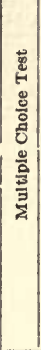 } & 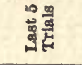 & थ \\
\hline & 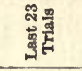 & 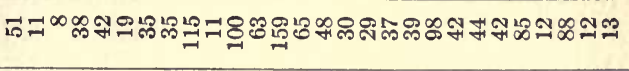 \\
\hline & 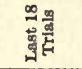 & 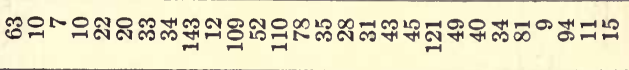 \\
\hline & 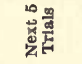 & N \\
\hline & 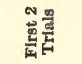 & \# \\
\hline \multirow{12}{*}{ 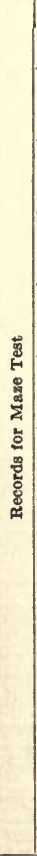 } & 串进 & 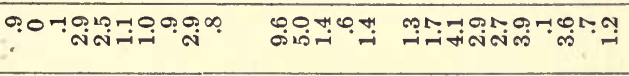 \\
\hline & 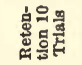 & 花 \\
\hline & 突案离 & 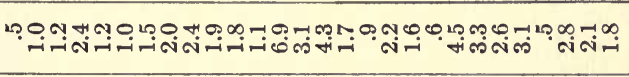 \\
\hline & 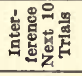 & 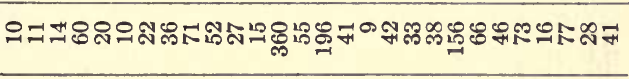 \\
\hline & 岩总题 & 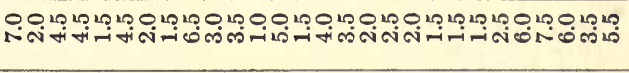 \\
\hline & 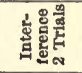 & 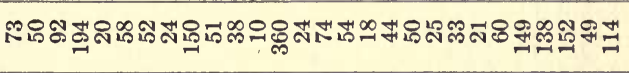 \\
\hline & 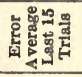 & 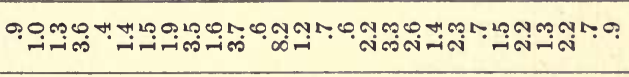 \\
\hline & 象点 & m $0 \times$ N \\
\hline & 运量 & 프유 \\
\hline & 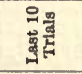 & 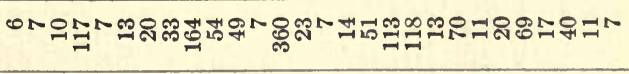 \\
\hline & 舫 & ํํ \\
\hline & 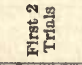 & कर \\
\hline & $\stackrel{\circ}{Z}$ & 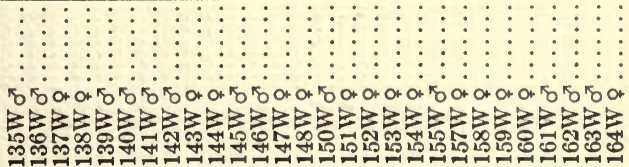 \\
\hline
\end{tabular}




\begin{tabular}{|c|c|c|}
\hline \multirow{6}{*}{ 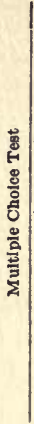 } & 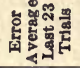 & 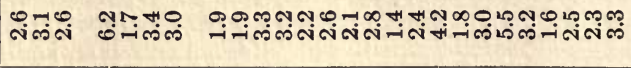 \\
\hline & 象罚 & 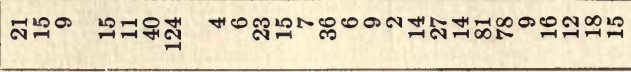 \\
\hline & 象弯 & 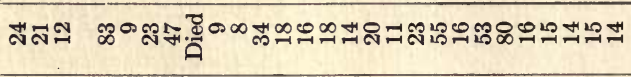 \\
\hline & 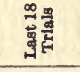 & 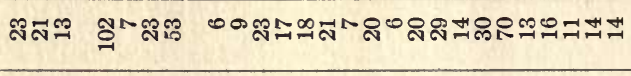 \\
\hline & 离递 & 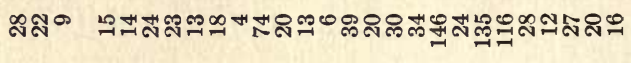 \\
\hline & 喜愛 & 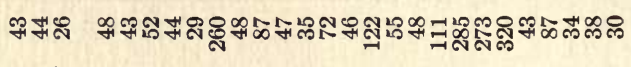 \\
\hline \multirow{12}{*}{ 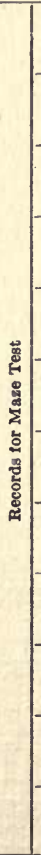 } & 军 & 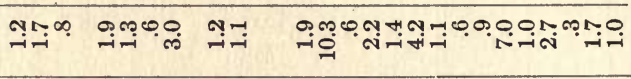 \\
\hline & 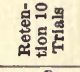 & 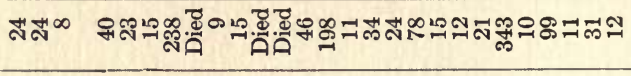 \\
\hline & 悹离 & 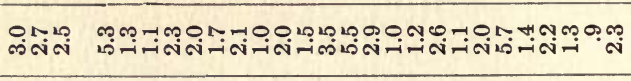 \\
\hline & 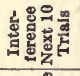 & 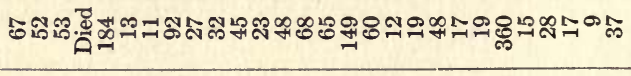 \\
\hline & 悹兽 & 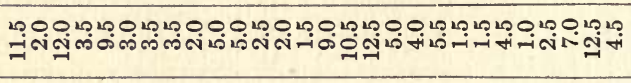 \\
\hline & 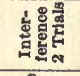 & 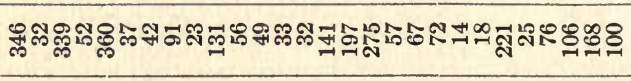 \\
\hline & 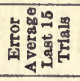 & 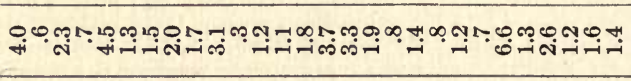 \\
\hline & 㟽惫 & 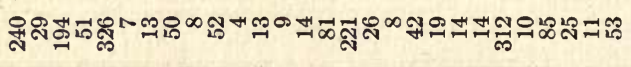 \\
\hline & 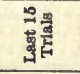 & 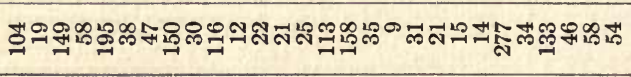 \\
\hline & 语 & 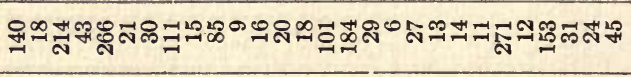 \\
\hline & 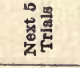 & 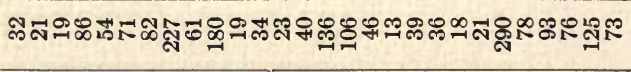 \\
\hline & 䓛峦 & 苛 \\
\hline & 字 & 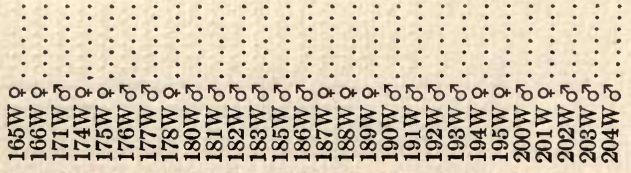 \\
\hline
\end{tabular}




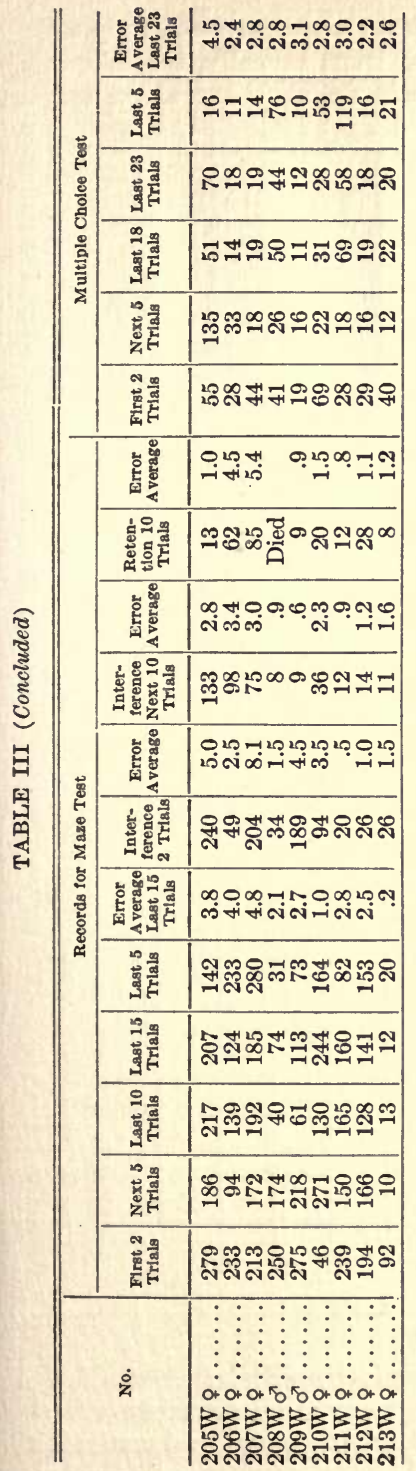


became "tired" of the problem and lost their adjustment, or in other words, the test had been carried too long; secondly, the following explanation may be given: the drop in the sixth day of the test is

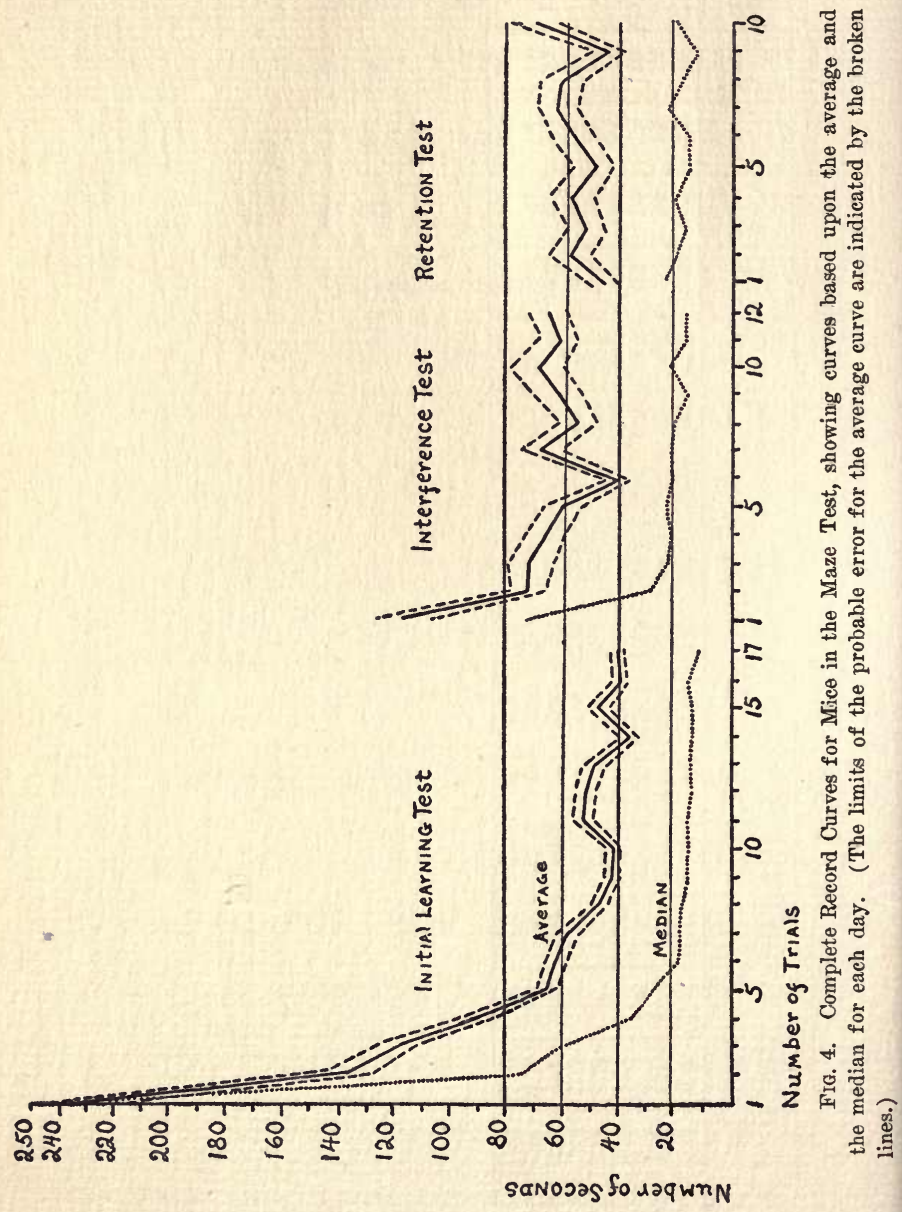

not significant and represents a chance irregularity which would disappear from the curve if a still greater number of animals was used. As there is no evidence to support the first of these explanations, it 
is probable that the second solution is the correct one. We can, therefore, say that the interference as shown in this experiment was not a transitory thing, being evident for only one or two trials after its application, but instead, it exerted an influence over a number of trials and prevented the animals from attaining the same degree of proficiency that they had previously shown in a similar task. However, if the interference test had been continued it is possible that the curve would have reached as low a record as that given by the initial learning test.

TABLE IV

Complete Records of a Famit Consisting Mostly of Yellow Indrviduals IN THE MAZE TEST

\begin{tabular}{|c|c|c|c|c|c|c|c|c|c|c|c|}
\hline No. & $\begin{array}{c}\text { First } \\
2 \\
\text { Trials }\end{array}$ & $\begin{array}{c}\text { Next } \\
5 \\
\text { Trials }\end{array}$ & $\begin{array}{c}\text { Last } \\
10 \\
\text { Trials }\end{array}$ & $\begin{array}{c}\text { Last } \\
15 \\
\text { Trisls }\end{array}$ & $\begin{array}{l}\text { Error } \\
\text { Aver- } \\
\text { age }\end{array}$ & No. & $\begin{array}{c}\text { First } \\
\mathbf{2} \\
\text { Trials }\end{array}$ & \begin{tabular}{c|c} 
Next \\
5 \\
Trials
\end{tabular} & $\begin{array}{c}\text { Last } \\
10 \\
\text { Trials }\end{array}$ & \begin{tabular}{|c} 
Last \\
15 \\
Trials
\end{tabular} & \begin{tabular}{|c} 
Error \\
Aver- \\
age
\end{tabular} \\
\hline 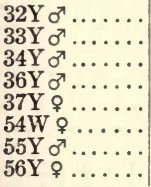 & $\begin{array}{l}225 \\
154 \\
186 \\
354 \\
137 \\
360 \\
360 \\
360\end{array}$ & $\begin{array}{r}109 \\
186 \\
88 \\
55 \\
20 \\
36 \\
242 \\
130\end{array}$ & \begin{tabular}{r|}
71 \\
42 \\
39 \\
28 \\
16 \\
34 \\
103 \\
103
\end{tabular} & $\begin{array}{r}83 \\
90 \\
56 \\
37 \\
17 \\
35 \\
150 \\
112\end{array}$ & $\begin{array}{r}1.7 \\
.5 \\
1.0 \\
.9 \\
1.2 \\
.7 \\
3.5 \\
2.0\end{array}$ & 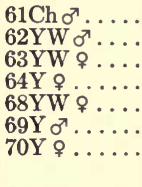 & $\begin{array}{l}360 \\
312 \\
243 \\
360 \\
112 \\
177 \\
234\end{array}$ & $\begin{array}{r}202 \\
90 \\
130 \\
182 \\
71 \\
41 \\
223\end{array}$ & $\begin{array}{r}30 \\
18 \\
38 \\
113 \\
65 \\
9 \\
75\end{array}$ & $\begin{array}{r}87 \\
42 \\
69 \\
136 \\
67 \\
19 \\
124\end{array}$ & $\begin{array}{l}1.0 \\
1.5 \\
1.2 \\
2.3 \\
2.0 \\
. .7 \\
2.3\end{array}$ \\
\hline
\end{tabular}

\section{TABLE V}

Complete Records of a SMall Family Showing Good Records in the Maze TEST

\begin{tabular}{|c|c|c|c|c|c|c|c|c|c|c|c|}
\hline No. & $\begin{array}{c}\text { First } \\
2 \\
\text { Trials }\end{array}$ & $\begin{array}{c}\text { Next } \\
5 \\
\text { Trisls }\end{array}$ & $\begin{array}{c}\text { Last } \\
10 \\
\text { Trials }\end{array}$ & $\begin{array}{c}\text { Last } \\
15 \\
\text { Trials }\end{array}$ & $\begin{array}{l}\text { Error } \\
\text { Aver- } \\
\text { age }\end{array}$ & No. & $\begin{array}{c}\text { First } \\
2 \\
\text { Trials }\end{array}$ & $\begin{array}{c}\text { Next } \\
5 \\
\text { Trials }\end{array}$ & $\begin{array}{c}\text { Last } \\
10 \\
\text { Trials }\end{array}$ & \begin{tabular}{|c|} 
Last \\
15 \\
Trials
\end{tabular} & $\begin{array}{c}\text { Error } \\
\text { Aver- } \\
\text { age }\end{array}$ \\
\hline 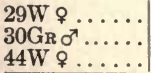 & $\begin{array}{r}229 \\
58 \\
297\end{array}$ & $\begin{array}{r}9 \\
43 \\
16\end{array}$ & $\begin{array}{r}8 \\
33 \\
7\end{array}$ & $\begin{array}{r}8 \\
36 \\
10\end{array}$ & $\begin{array}{r}1.3 \\
1.0 \\
.5\end{array}$ & $\begin{array}{l}45 \mathrm{~W} \text { \% } \ldots . . . \\
46 \mathrm{GR} \sigma^{7} \ldots \ldots \\
47 \mathrm{~B} 1 \sigma^{\top} \ldots . .\end{array}$ & $\begin{array}{l}142 \\
141 \\
150\end{array}$ & $\begin{array}{r}13 \\
9 \\
34\end{array}$ & $\begin{array}{r}5 \\
4 \\
29\end{array}$ & $\begin{array}{r}8 \\
6 \\
31\end{array}$ & $\begin{array}{r}.5 \\
.5 \\
1.0\end{array}$ \\
\hline
\end{tabular}

It is interesting to note that Hunter and Yarbrough found that interference occurred between an old habit and the formation of a new one, in their study of the auditory habits in the white rat." The following is quoted from their results: "Habit interference occurs in the white rat between a first habit and the formation of the second one." "Interference is most marked between the end of the perfected habit and the beginning of the new habit." "Habit interference may serve greatly to slow up the formation of a new habit." The results of this investigation agree, in the main, with the statements that have just been quoted, but, although the interference effect eaused a sharp rise in the time curve, and the interference was

${ }^{2}$ Walter S. Hunter and Jas. N. Yarbrough, "The Interference of Auditory Habits in the White Rat," The Journal of Animal Behavior, Vol. 7, No. 1. 
evident throughout the subsequent trials, yet it did not appear to slow up the formation of a new habit to as great a degree as might be expected from the nature of the behavior that was tested. The quick recovery from the interference effect suggests that the behavior of the animals of this investigation shows a considerable amount of flexibility. As was previously stated, the animals took only half as much time to go through the maze on the day when the interference was given as they did on the first day they were tested, and this shows that an accelerating transfer effect from the previous training was operating to counteract the slowing up of the interference.

In order to more earefully analyze the behavior of the mice the median record was calculated for each day's performance, and a curve based upon the same is represented by the dotted lines in Fig. 4. It may be noted that for each test the curve based on the median falls considerably below the corresponding curve for the average. The essential character of the curves, found by these different meth. ods, is the same; except that the curve based upon the median is more regular than the one found from the average. In the interference test the curve for the median records is much more regular than that of the average curve for the same test, while no disturbance at all is to be noted at the sixth day of that test. The character of the curve based on the median supports what has already been said concerning the permanence of the interference effects over a number of trials.

The retention test shown in Fig. 4 was given immediately after the mice had been tested in the multiple choice test, and may represent a certain amount of training acquired there. The average time for the last ten trials of the interference test is $60.26 \pm$ P.E. 4.7, while the average time for the ten trials in the retention test is 52.81 \pm P.E. 4.7. The superiority of the average retention test in time is nearly twice its P.E., indicating a fair reliability. The superiority of the retention test may be due to the presence of one or more of the following conditions: (1) A mere carrying over of capacity attained in the interference test. (2) The dying out of bonds developed in the negative test (which in this case was the initial learning test), and the strengthening of bonds developed in the interference test. (3) The transfer of capacity developed in the multiple choice test. Now 1 is not likely because the average record made in the retention test was much better than that in the interference test even after a considerable interval of time. It is possible that the condition in 2 may account for the facts, but there is no direct con- 


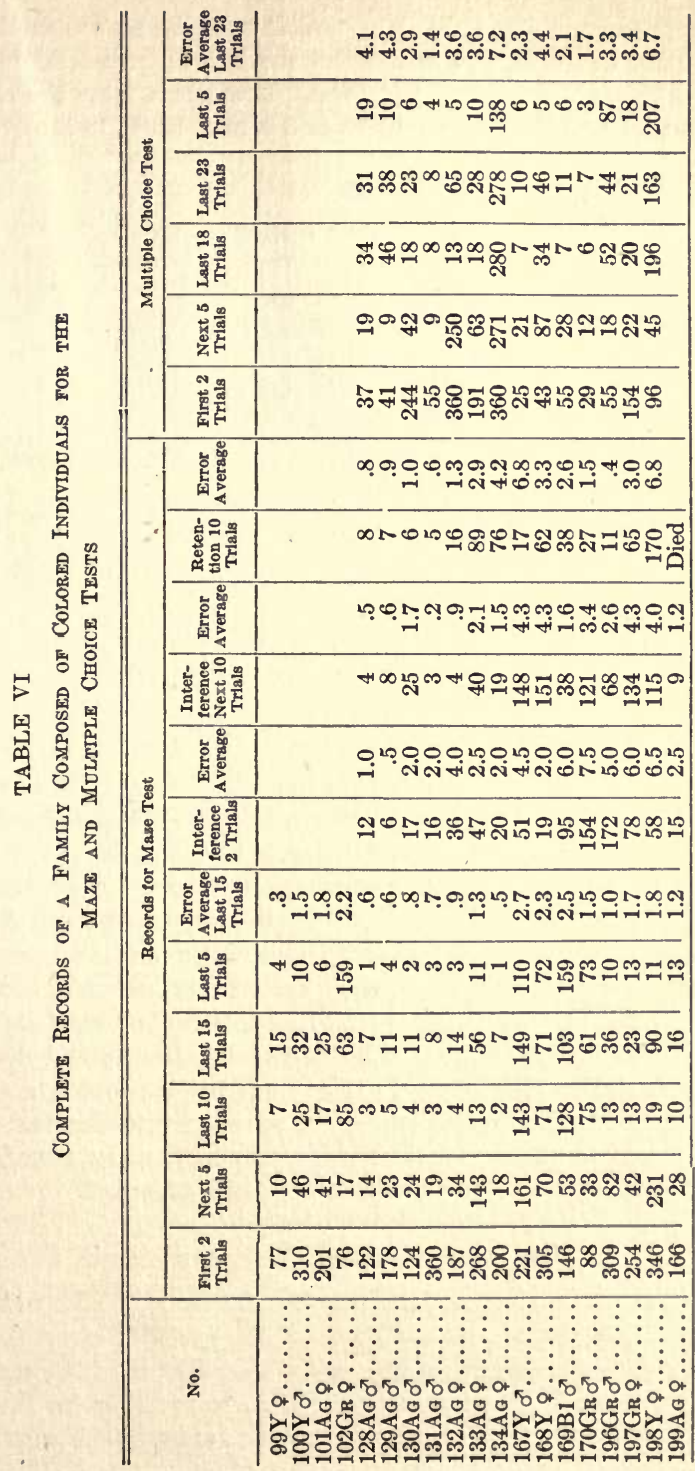


firmatory evidence from the data, and it must be remembered that the original test, although older than the interference test, still received a greater amount of repetition. It appears from the results of the experiment that the condition in 3 is most likely to account for

\section{TABLE VII}

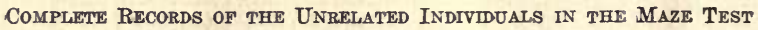

\begin{tabular}{|c|c|c|c|c|c|c|c|c|c|c|c|}
\hline No. & \begin{tabular}{|c|} 
First \\
2 \\
Trials
\end{tabular} & \begin{tabular}{|c|} 
Next \\
5 \\
Trials
\end{tabular} & $\begin{array}{c}\text { Last } \\
10 \\
\text { Trtals }\end{array}$ & \begin{tabular}{|c|} 
Last \\
15 \\
Trials
\end{tabular} & $\begin{array}{c}\text { Error } \\
\begin{array}{c}\text { Aver- } \\
\text { age }\end{array}\end{array}$ & No. & $\begin{array}{c}\text { First } \\
2 \\
\text { Trials }\end{array}$ & $\begin{array}{c}\text { Next } \\
5 \\
\text { Trials }\end{array}$ & \begin{tabular}{|c|} 
Last \\
10 \\
Trials
\end{tabular} & \begin{tabular}{|c|} 
Last \\
15 \\
Trials
\end{tabular} & $\begin{array}{c}\text { Error } \\
\text { Aver- } \\
\text { age }\end{array}$ \\
\hline 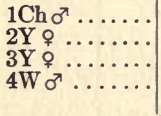 & $\begin{array}{r}212 \\
285 \\
316 \\
77\end{array}$ & $\begin{array}{r}48 \\
213 \\
55 \\
18\end{array}$ & $\begin{array}{r}11 \\
103 \\
63 \\
14\end{array}$ & $\begin{array}{r}23 \\
140 \\
61 \\
16\end{array}$ & \begin{tabular}{r|}
1.0 \\
5.1 \\
3.3 \\
.7
\end{tabular} & $\mid \begin{array}{c}5 \mathrm{~W} \text { \& } \ldots \ldots \\
28 \mathrm{~W} \sigma^{7} \ldots \ldots \ldots \\
31 \mathrm{GR} \text { \& } \ldots \ldots \\
85 \mathrm{~W} \sigma^{7} \ldots \ldots \\
90 \mathrm{Ch} \text { \& } \ldots \ldots\end{array}$ & $\begin{array}{r}74 \\
291 \\
130 \\
131 \\
202\end{array}$ & $\begin{array}{l}22 \\
38 \\
78 \\
14 \\
81\end{array}$ & $\begin{array}{r}8 \\
5 \\
15 \\
9 \\
13\end{array}$ & $\begin{array}{l}12 \\
17 \\
38 \\
11 \\
35\end{array}$ & $\begin{array}{r}.6 \\
1.0 \\
1.0 \\
.8 \\
1.0\end{array}$ \\
\hline
\end{tabular}

the facts; that is, the transfer of eapacity developed in the multiple choice test accounted for the superiority of the retention test, by virtue of the better adjustment that the animals received to the experiment as a whole, and by practise in the elimination of fruitless movements. The number of seconds required for the average mouse to complete the first trial of the retention test is below all but one of the records that the same mice made in the interference test, and it is noteworthy that the curve for the retention test based on the daily average, is not similar to either of the preceding curves, but is nearly flat, except for a slight rise at the last trial. Since the average animal did not start with a high time record, it is evident that it did not need to learn the task all over again, but showed a considerable amount of permanence of association for the previously learned task.

The curve for the retention test, based on the median record for each day, confirms, in the main, what has already been said concerning this test. The curve for the median is also flat, the four high points all reaching to about a score of twenty seconds, and it again shows the relative superiority in the record for the first day of the test. Also, taken day by day, the records for the retention test, with a single exception, show the retention test with daily records superior to the corresponding ones of the interference test.

\section{(d) Results for Multiple Choice Test}

Fig. 5 gives complete record curves for the same 71 mice as tested by the multiple choice, and the limits of the probable error, for the curve based on the daily average, are indicated in the same manner as explained for the previous curves. The average time for the first trial in the maze test is 236 seeonds as compared with 91 seconds as 
the average for the first trial of the multiple choice test. How much this difference is due to what the average animal acquired in the first experiment can not be determined since the tests themselves are markedly different. ${ }^{10}$ In the first place, the distance to be traversed

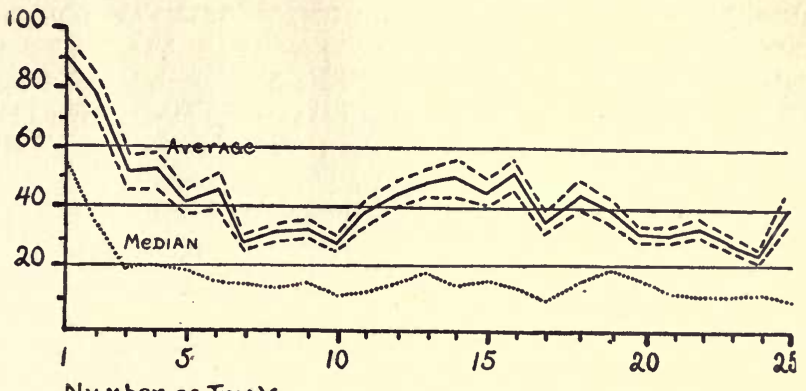

Number of Trials

Fig. 5. Complete Record Curves for Mice in the Multiple Choice Test, showing curves based upon the average and the median for each day. (The limits of the probable error for the average curve are indicated by the broken lines.)

in the multiple choice test is much shorter than in the maze test, and the intensity of punishment is greater in the former case because there the electric shock was used. Also color clews, and the fact that it was necessary for the animal to go through only one door, tend to lessen the average time in the multiple choice test. As indicated in the previous discussion, there was no doubt a transfer effect in learning from the first task to the second, that would again result in shortening the time in the multiple choice test. This was due; first, to a better general adaptation to the experiment as a whole, which was carried over from the maze test; and secondly, to the fact that an important element was common to both tasks, namely, that in each case the animal learned to escape from confinement by means of a door that could be pushed open. It is interesting to note at this point that Yerkes in his study of the dancing mouse ${ }^{2}$ (see page 263) found that experience in one labyrinth made the learning in a second labyrinth much easier. "Those individuals whose first labyrinth training was in (labyrinth) $C$ made their first correct trip as the result of 19.7 trials, whereas those which had previously been trained in labyrinth $B$ were able to make a correct trip as the result of only 7.0 trials. Similarly the table shows that training in $C$ rendered the 10 This point is being more closely studied in an experiment, now under way. 
subsequent learning in $B$ easier." The average curve in Fig. 5 indicates that there is practically no increase in learning between the seventh trial and the twenty-fifth. A fairly uniform decrease in time occurs from the first to the seventh day, when an average speed of twenty-six seconds was made. The only other performance that bettered this record was made on the twenty-fourth day, when an average time of twenty-four seconds was recorded. The number of trials in the multiple choice test could have been much less and still sufficient for the average mouse to learn the maze. It was impossible to determine that more trials were given than were necessary until the experiment was well started. In fact, the experimenter arbitrarily chose twenty-five as the number of trials because he thought it would take the average mouse longer to learn the second task than the first. As explained above, the results of the experiments disapproved this assumption.

In the multiple choice test, the curve based on the median record for each day, as in the previous tests, is considerably below the corresponding curve for the average. The curves here are essentially similar, and it may be noted that the curve for the median, after the second trial, never rises higher than twenty seconds or lower than ten. 


\section{CORRELATIONS IN LEARNING RECORDS}

VARIOUS correlations have been calculated for performance in one task with performance in another, and between groups of trials within a single task. The correlation have all been positive, varying from 0.11 to 0.85 as described below. A complete list of the correlations is given in Table VIII. The Pearson formula,

TABLE VIII

Results of Corretations

\begin{tabular}{|c|c|c|}
\hline No. & Things Correlated & Correlations \\
\hline 1. & Time in last 15 trials of maze test with error average in same task & +0.85 \\
\hline 2. & $\begin{array}{l}\text { Time in first group of } 5 \text { trials in maze test with the time in last } \\
\text { group of } 5 \text { trials in maze test } \ldots \ldots \ldots \ldots \ldots \ldots \ldots \ldots\end{array}$ & +0.46 \\
\hline 3. & Time in last 15 trials of maze test with the time in retention test. & +0.35 \\
\hline 4. & 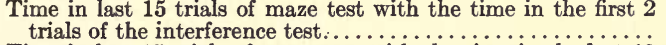 & +0.55 \\
\hline 5. & 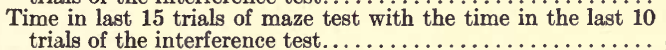 & +0.49 \\
\hline 6. & $\begin{array}{l}\text { Time in last } 23 \text { trials of Multiple Choice test with error average } \\
\text { made in same test. }\end{array}$ & +0.82 \\
\hline 7. & $\begin{array}{l}\text { Time in first group of } 5 \text { trials in Multiple Choice test with the } \\
\text { time in last group of } 5 \text { trials in Multiple Choice test....... }\end{array}$ & +0.25 \\
\hline 8. & $\begin{array}{l}\text { Time in last group of } 15 \text { trials in maze test with the time in last } \\
\text { group of } 23 \text { trials in Multiple Choice test................ }\end{array}$ & +0.11 \\
\hline
\end{tabular}

$$
r=\frac{\Sigma(x \cdot y)}{\sqrt{\Sigma x^{2}} \cdot \sqrt{\Sigma y^{2}}}
$$

was used for the correlations numbered in the table as 1, 2, 6 and 7 . Because the remaining correlations, $3,4,5$ and 8 were made between two groups both from asymmetrical distributions, the ranking method was used with the following formula:

$$
r=1-\frac{6 \Sigma D^{2}}{n\left(n^{2}-1\right)}
$$

The ranking method was employed so that undue weight would not be given to the few extreme cases in the skewed distributions. This disadvantage did not occur in the correlations made, between time and error, and performance at the beginning and end of the tests, so in these cases the Pearson formula was used.

The correlation between the time in the initial learning period in the maze test with the errors made during that performance 
amounted to +0.85 . A similar coefficient of correlation of +0.82 was found to hold between the last 23 trials of the multiple choice test and the errors made in that task. These results are what one might naturally expect to find, namely, that the animal that made many errors required more time. The conclusion need not hold, however, for the type of behavior that this investigation deals with, because it might very well be that a stupid animal was one likely to sit in a corner of the maze and make a poor time record, but a good error record. These two high correlations are thus seen to give a measure of the activity of the animals in each task, and they show the value of the tests that were used, in that each was adapted to the instinctive behavior of the animals tested. ${ }^{11}$ The native equipment of the mice no doubt adapted them to finding their way through narrow passages and forcing their bodies through small openings.

A low positive correlation of 0.11 was found to hold for the relation between the initial learning period in the maze test and the last 23 trials in the multiple choice test. As previously discussed, the time values in the two tasks that were correlated are not comparable, and this fact may account for the lowness of the coefficient of correlation.

A correlation was made between performance at the beginning and close of the trials, and in this case the first group of five trials was correlated with the last group of five. For the maze test this correlation amounted to +0.46 , which represented a fairly strong correlation. A similar correlation between the first group of five trials and the last group of five trials in the multiple choice test gave a lower correlation of +0.25 .

The correlation between the initial learning period in the maze test and the retention test for the same task was found to be +0.35 . This indicated a fairly close relation between proficiency in a given task and the amount of association retained. A similar correlation between the same initial learning period in the maze test and the first

11 Guinea pigs have been used as subjects of another investigation and when tested in the maze, that apparatus was found to be very well suited to their irstinctive type of behavior. They have not as yet been tried in the multiple choice apparatus which was used in these experiments. The maze test, and the multiple choice as well, were found to be unsuited to the average native equipment of a litter of seven English Bulldog puppies that also have been tested. Four out of the seven dogs failed completely to learn the task, sitting in a corner of the maze and barking disconsolately at the gates. They held back from passing through an opening through which an average mouse would at once venture. Two of the dogs learned very slowly, while one made a good record. The dogs were more interested in looking for the experimenter and responding to the slightest noise he would inadvertently make, than in paying attention to the maze problem itself. 
two interference trials was +0.55 ; and for the same period in the maze test with the last ten trials of the interference test the correlation amounted to $+\mathbf{0 . 4 9}$.

The above correlations tend to show: first, that the animal that does well in any one task is likely to retain more than one that does not do well; secondly, time and error are closely related in the types of behavior that this investigation deals with, and one is a measure of the other; thirdly, an animal that does well in the beginning of a task is more likely to do well at the end that an animal that is slow in learning; fourthly, the animal that did well in the maze task exhibited greater adaptability in behavior than one that did not do well, as shown by a comparison of the interference records. 


\section{FAMILY RESEMBLANCES}

IN the preliminary report of these experiments it was found that the mean variation of the entire group of 90 mice, including mice from all the strains that had been tested up to that date, amounted to 35.6. This means that any mouse picked at random from that group would be likely to vary from the average by 35.6 seconds. In order to find whether mice of the same litter vary less than unrelated individuals, the mean variations for each of the eighteen families was calculated, and these, when weighted for size of family, were found to be 20.2. It was, therefore, stated that the resemblance in behavior between mice belonging to the same litter was nearly twice as great as between unrelated individuals, and that this corresponded to a coefficient of correlation in the neighborhood of 0.5 for brothers, as found by Pearson, Thorndike and others. It is probable, however, that in this case the mean variation was increased for the unrelated individuals, and the family resemblance correspondingly made to appear greater, due to the fact that the mixed group was made up of two fairly distinct strains of mice, a quick white group and a slow yellow group.

As previously stated the above calculation was made from the results in only one task, namely, the initial learning period of fifteeu trials in the maze test. When the mean variations were calculated for the four distinct tests that were later used, and in which considerably more animals were tested, there was apparently no greater resemblance, judged by this method of variation, between animals of the same litter than between unrelated individuals. In order to discount the inevitable reduction in mean variation that resulted from the grouping of the individuals into family lots, in which case the mean variations were calculated from the family averages, all the mice that belonged to the family groups were rearranged according to chance into other groups of exactly the same size. Then the mean variations for the groups formed by chance arrangement were calculated in exactly the same manner as was previously done for the true family groups. A comparison of the two results showed a strict similarity in mean variation in each of the four tests; so that the mean variation for the groups of related individuals was not less than, but practically identical with the variation that obtained for the same individuals grouped by a chance arrangement. Later in this thesis, when a detailed study of the family histories is taken up, the records for the various litters will give further light on this subject of family resemblances, and individual variations. 

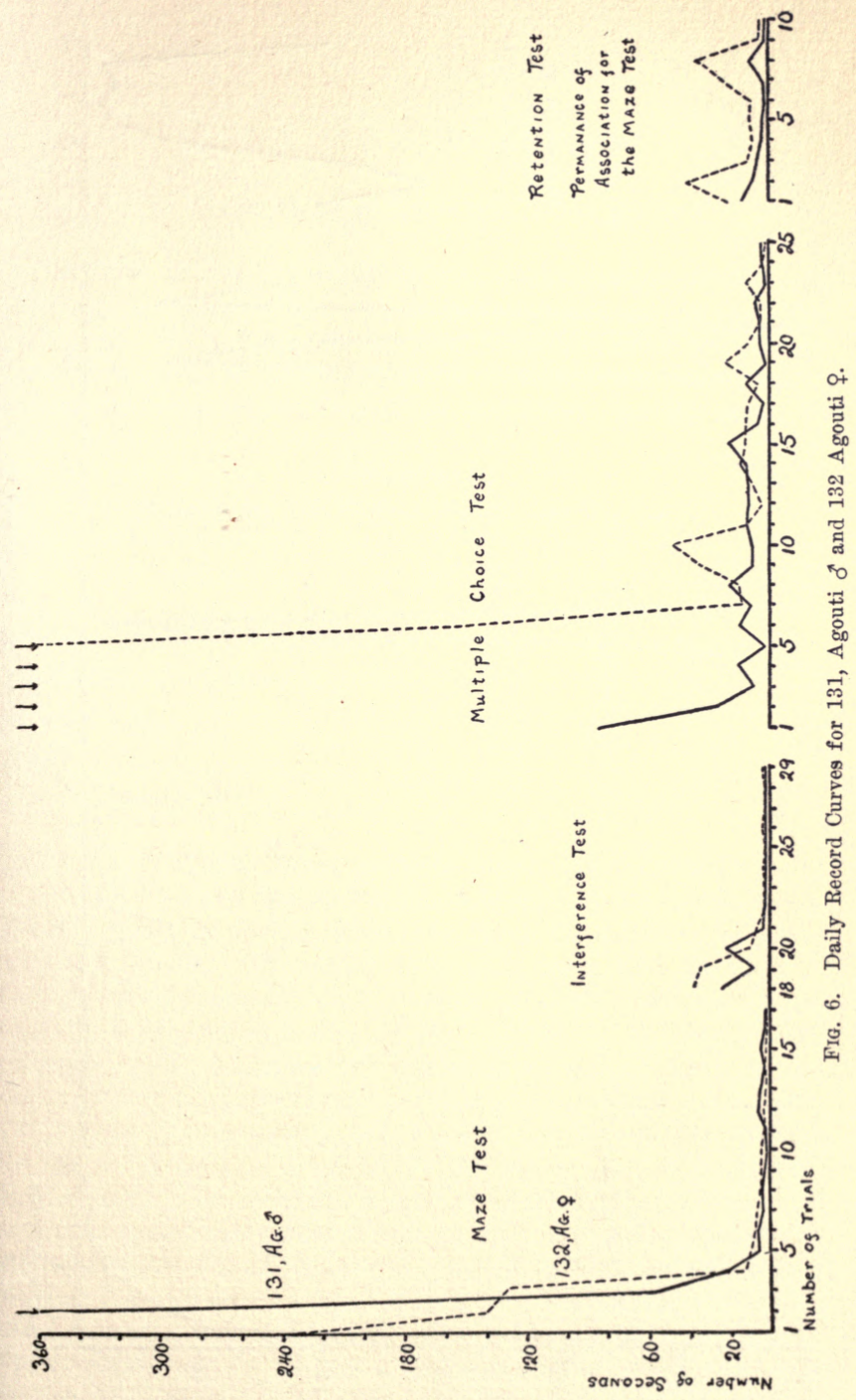

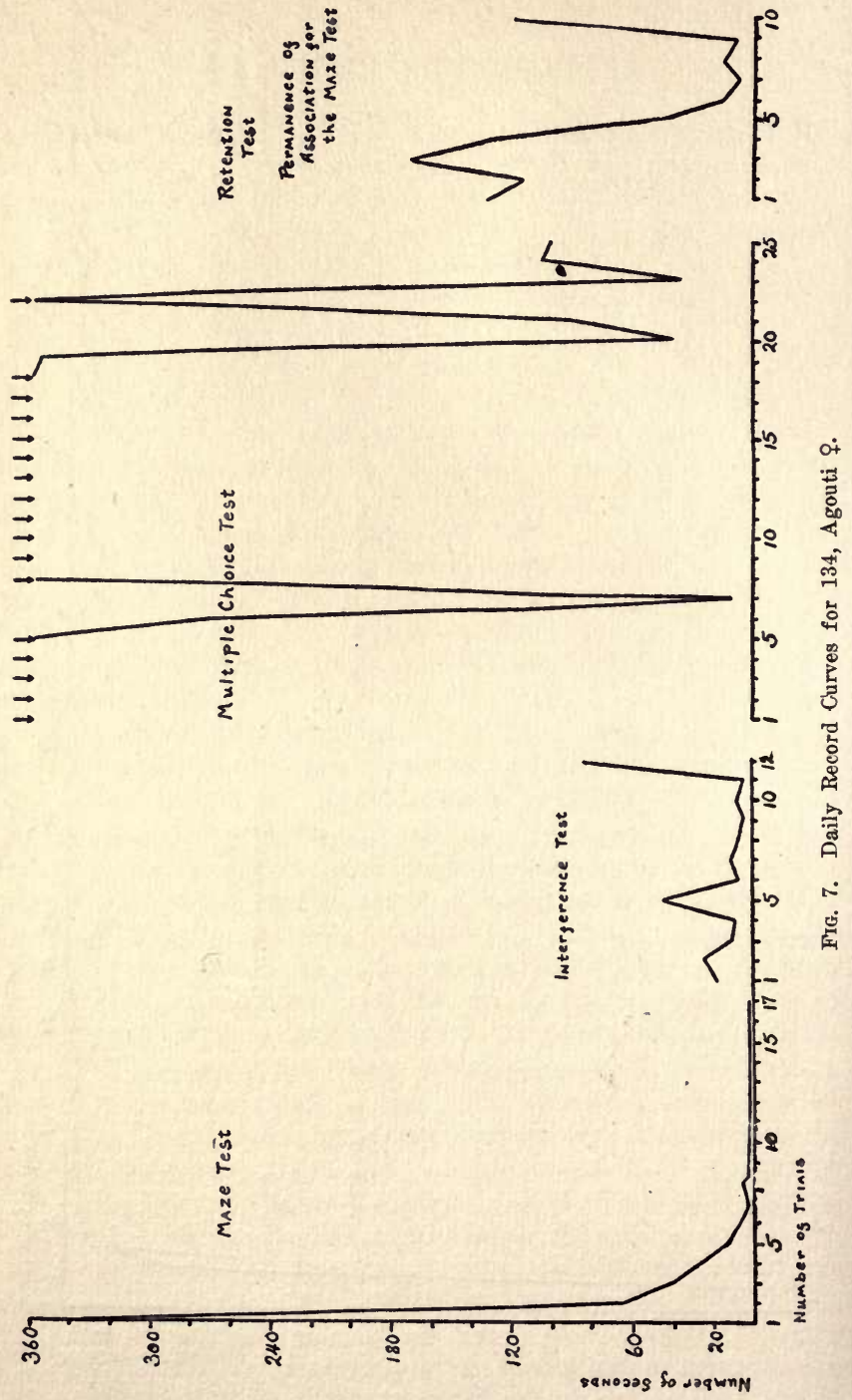


\section{SEX DIFFERENCES}

\section{(a) Differences in Time and Error Records}

IN Table IX. the males and females are grouped separately, and their average times and errors are given for the various tasks that were used. The preliminary report of this investigation showed that there were small sex differences for performance in the initial learning period in the maze test, and the differences that did exist were

TABLE IX

Averages for Sex Differences and Sex Variability

\begin{tabular}{|c|c|c|c|c|c|}
\hline Tests & $\underset{\text { Nex and }}{\text { Sex }}$ & $\mid \begin{array}{c}\text { A verage No. } \\
\text { of secs. } \\
\text { per Trlal }\end{array}$ & $\begin{array}{l}\text { Mean Varl- } \\
\text { atlons in } \\
\text { Seconds }\end{array}$ & $\begin{array}{c}\text { Probable } \\
\text { Error }\end{array}$ & $\begin{array}{l}\text { Average No. } \\
\text { of Errors } \\
\text { per Tria }\end{array}$ \\
\hline $\begin{array}{l}\text { Initial Learning Period, Maze Test.. } \\
\text { Interference Test, } 10 \text { Trials........ } \\
\text { Retention Test ............... } \\
\text { Multiple Choice Test . . . . . . . . }\end{array}$ & $\begin{array}{l}93 \sigma^{7} \\
90 \% \\
34 \sigma^{\circ} \\
37 \% \\
34 \sigma^{7} \\
37 \% \\
34 \sigma^{7} \\
37 \%\end{array}$ & $\begin{array}{l}43.80 \\
64.77 \\
37.76 \\
80.96 \\
27.58 \\
76.00 \\
25.76 \\
52.08\end{array}$ & $\begin{array}{l}33.5 \\
53.3 \\
29.0 \\
56.8 \\
21.8 \\
59.1 \\
17.0 \\
35.1\end{array}$ & $\begin{array}{l} \pm 2.9 \\
\pm 4.7 \\
\pm 4.3 \\
\pm 8.0 \\
\pm 3.2 \\
\pm 8.3 \\
\pm 2.5 \\
\pm 4.9\end{array}$ & $\begin{array}{l}1.2 \\
1.7 \\
1.6 \\
2.8 \\
1.4 \\
2.9 \\
2.8 \\
3.9\end{array}$ \\
\hline
\end{tabular}

well within the limits of the probable error. With a larger number of animals, 93 males and 90 females, it was found that in the initial learning period in the maze test, the males did considerably better than the females. The males made an average time per trial of $43.80 \pm$ P.E. 2.9 seconds, and 1.2 error per trial, while the females made a corresponding record of $64.77 \pm$ P.E. 4.7 seconds and 1.7 error per trial. As previously stated, there were 71 animals that were tested in the interference, retention and multiple choice tasks, and of these 34 were males and 37 females. As indicated in the table for sex differences, in all three of the above mentioned tests the females took, on the average, twice as many seconds to learn the tests and made considerably more errors per trial than did the males. In the interference test of ten trials the males made an average time of $37.76 \pm$ P.E. 4.3 seconds and 1.6 error per trial, while in the same task the females took $80.96 \pm$ P.E. 8.0 seconds and 2.8 error per trial. The retention test records gave a similar result; the males making an average of $27.59 \pm$ P.E. 3.2 seconds per trial and 1.4 error per trial, and again the females took more than twice as long to perform the 
same task, namely, $76.00 \pm$ P.E. 8.3 seconds and 2.9 error per trial. In the multiple choice test the males took $25.76 \pm$ P.E. 2.5 seconds and 2.8 error per trial, while the females made an average of $52.08 \pm$ P.E. 4.9 seconds and 3.9 error per trial. The final average of the males for all four tests amounted to $33.72 \pm$ P.E. 4.9 seconds per trial, while that of the females was 68.45 seconds. This shows that the females in the total record took slightly more than twice as long to learn the tests as did the males. ${ }^{12}$

\section{(b) Comparative Distributions of the Males and Females}

In Fig. 8 are given the comparative distributions for the 34 males and 37 females that have been tested in all four of the tasks for which time averages are given in Table IX. The distributions for the males and females, in the initial learning period of the maze test, show that the curve for the males is skewed, for, although there is an equal number of individuals, namely, 12 , between 0 and 20 seconds, and 20 and 40 seconds, still from that point on the eurve drops quickly, while no individuals are to be found beyond 160 seconds. The distribution curve for the females shows that the mode for that sex is about the same as that found for the males, also that several females are distributed toward the right end of the figure, which indicates that they were the animals that made poor time records. Eight females are to be found between 0 and 20 seconds, and while the curve for this sex drops steadily until 80 seconds is reached, still it rises steadily from that point until it reaches a maximum in the region between 140 and 160 seconds, where five females are to be found. This almost gives the curve a bimodal appearance, but there is no evidence at hand which leads the writer to believe that there were two distinct classes of females among the mice that were tested. The important point to be noted in Fig. 8 is that there were six females that exceeded any of the records made by the males; there

12 It might be expected that this sex difference would have its effect on the validity of the correlations that have already been given, since they show that the total population was made up of two groups, one, the males, which were relatively quick learners, and the other the females, relatively slow learners, but the accompanying correlations that were made for the separate sexes show that they follow rather elosely the combined correlations that have been given in Table VIII. Correlating the last 15 trials of the maze test with the first two trials of the interference test gave the following correlations: $\sigma^{2} s=+.60, \rho_{s}=+.54$. The correlations for the same 15 trials of the maze test with the last 10 trials of the interference test gave: $\delta s=+.35$, o $s=+.49$. Again the same maze trials when ecrrelated with the retention test gave the following correlations: $\delta^{i} \mathrm{~s}=+.18$, os $=+.27$. The last sex correlation was made between the last 15 trials of the maze test and the last 23 trials of the multiple ehoice test, and here the following correlations were found: $\delta \mathrm{s}=-.26, q \mathrm{~s}+.16$. 
were two females between 180 and 200 seconds; one between 200 and 220 seconds; one each between 240 and 260 , and 260 and 280 seconds; and finally one female that failed completely.
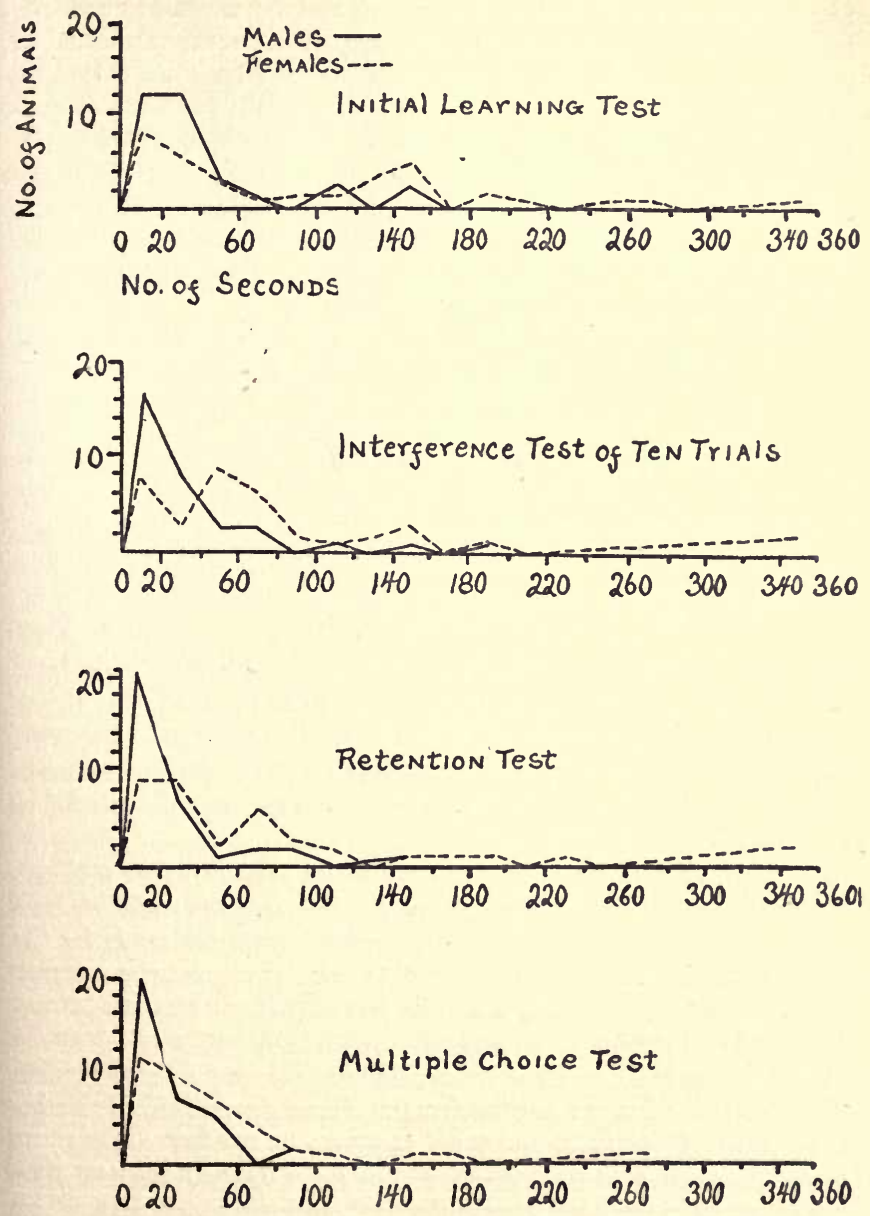

FIG. 8. Distribution Curves for the Males and Females for all Tasks. In each case the number of animals is given by the ordinate, while the abscissae represent the number of seconds The males are represented by the solid lines and the females by the broken lines. 
The distribution curves for the males and the females, for the interference test of ten trials in the maze, are also given in Fig. 8. Here it is to be seen that the curve for the males is distinctly skewed. Seventeen males are grouped between 0 and 20 seconds; eight between 20 and 40 seconds, and from there on the curve is similar to the one made by the same animals in the initial learning period of the maze test, but in the present case no males are to be found that took, on the average, longer than 200 seconds to complete the test. This figure shows that the mode for the females is to the right of the mode for the males; the greatest number of females, namely nine, are to be found between 40 and 60 seconds. The curve for the females is irregular, again showing a superiority in favor of the males, while here two females failed to learn the test.

The distribution curves of both sexes for the retention test show that the curve for the males is similar to the one above that we have just examined. It is skewed, with the mode between 0 and 20 seconds, where twenty-one animals are to be found, while no records for the males exceed 160 seconds. The curve for the females is less skewed than that of the males; an equal number of individuals, namely nine, are to be found between 0 and 20 seconds, and 20 and 40 seconds; the curve then drops quickly, but rises again in the region between 60 and 80 seconds, where there are six animals. Then the curve for the females gradually falls, but again shows the same characteristic that is to be found in all the comparative distributions, namely, that a number of females are distributed beyond the maximum records made by the males in the same test. In this case five females made longer average time records than the males, and two of them failed to learn the test.

The distribution curves for the males and females in the multiple choice test are given at the bottom of Fig. 8 . Here the mode for both sexes is to be found between 0 and 20 seconds; but the curve for the males is steeper than the corresponding one for the females; twenty males being found between 0 and 20 seconds; seven between 20 and 40 seconds; five between 40 and 60 seconds, and finally two between 80 and 100 seconds, which is the maximum time record for the males. The distribution curve for the females shows eleven individuals between 0 and 20 seconds, and then, as shown in the figure, the curve drops at a regular rate; there being nine individuals in the next time group, seven in the next, four in the next, and two in the next, where the curves for both sexes meet. It is to be noted, however, that the same thing occurs here that was found in the three previous distributions, namely, that the females exceeded the maximum time records 
of the males that were tested with them at the same time. In this case one female is to be found in each of the following time regions: 100 to 120 seconds; 140 to 160 seconds; 160 to 180 seconds, and 260 to 280 seconds.

\section{(c) Variability of the Sexes}

An inspection of the probable errors of Table IX. indicates that the behavior of the females was much more variable than that of the males. The table gives in detail the variability of the sexes. In the initial learning period of the maze test the following record was made: mean variation males, 33.5 seconds; mean variation females, 53.3 seconds; while in the interference test of ten trials the mean variation for the males was 29.0 seconds; and for the females 56.8 seconds. The corresponding records in the retention test gave a mean variation for the males of 21.8 seconds and for the females 59.1 seconds. In the multiple choice test the mean variation for the males amounted to 17.0 seconds, while for the females 35.1 seconds. The average of the variations for all the tasks amounted to 25.3 seconds for the males and 51.0 seconds for the females. These figures show that the variability in the behavior of the females was about twice as great as that of the males.

The above results in sex differences and variations agree with those of Hubbert in her work on habit formation in the albino rat. ${ }^{13}$ The following is quoted from her results: "The general averages for an equal number of males and females show the males superior to the females in all points save one, that of absolute time. They finished in fewer trials, required less total time, and covered a smaller amount of distance in learning the problem than did the females, while their speed was slightly higher. . . . The mean variation from the time average is less for the males at all ages, their distance variation is less at the age of sixty-five days and three hundred days."

Yerkes found that for the behavior of the dancing mouse in the black-white discrimination tests: "The males almost invariably acquired a perfect habit quicker than the females ... (but) ... in the labyrinth test the female is as much superior to the male as the male is to the female in the discrimination tests. . . . A degree of proficiency in labyrinth ' $\mathrm{B}$ ' attained by the males after 7.0 trials was equaled by the females after 6.2 trials. In labyrinth ' $\mathrm{C}$ ' the males acquired a habit as a result of 18.7 trials; the females, as a result of 13.8. And similarly in labyrinth ' $D$,' 6.1 trials did no more for the males than 2.9 did for the females."

13 Hubbert: "The Effect of Age on Habit Formation in the Albino Rat," Behavior Monograph Series, No. 11, 1915. 
The results of the present investigation agree with those found by Yerkes concerning his discrimination test, but do not agree with his results for the labyrinth test. The multiple choice used in the present experiments was primarily designed to test discrimination, while tending to destroy position habit, and so it may be considered comparable to the discrimination test used by Yerkes. Here there is agreement, in that the males did better than the females, but in the maze test, which corresponds to Yerkes' labyrinth, the results of this investigation agree with Hubbert's and disagree with those of Yerkes. 


\section{INDIVIDUAL DIFFERENCES AND METHODS OF HABIT FORMATION}

We may now take up in more detail a study of the records made by a few of the animals that show typical or exceptional types of behavior, and also diseuss the observations made on the methods of habit fixation. In Figs. 6 and 7 are given samples of practise curves for several mice, showing the daily records in each group of trials, in the order that they were given. The arrows at the highest points on the curve indicate that the mouse did not pass through the maze or multiple choice test within 360 seconds.

In Fig. 6 are given the daily record curves for two agouti mice, $131 \mathrm{Ag} . \sigma^{1}$ and $132 \mathrm{Ag}$. ㅇ. Their average time records are given in Table VI. They are mice from a single litter and their records show, in both cases, very rapid and consistent learning in the maze test, remarkably slight interference effect at the eighteenth trial, followed by a complete recovery and very speedy time records from the twenty-first to the twenty-ninth trial. No. 131, whose record is indicated by the solid line, made a record in all the tasks which was considerably better than the average. It showed a very strong retention for the maze test, while the records in the multiple choice test, although very good, show a more irregular performance than in the maze test. This irregularity of performance in the multiple choice test appears typical for the mice that have been tested in this investigation, and the irregularity may be due to the factors peculiar to the test itself, or, as previously discussed, to interference effects from previous training. No. 132, whose record is indicated in Fig. 6 by a broken line, failed to get through the multiple choice test for the first five days; succeeding on the sixth day, it made fairly good records thereafter. These two mice were taken as examples, because they typify the characteristic manner in which good time records were made by the mice that were tested in these experiments. The writer refers to the method of learning by rhythm of movements, which also has been noted by Watson, Basset and others for white rats. It was noted, for instance, that mouse $132 \mathrm{Ag} q$, in the initial learning period in the maze test, never went to the elosed gate in the first compartment after the first two days of training. For a week of learning, from the fourth trial to the tenth inclusive, this mouse passed the first open gate successfully, but instead of going on to the open gate in the second compartment, the animal invariably made a detour 
TABLE X

Rhythm in the Production of Errors in the Maze Test

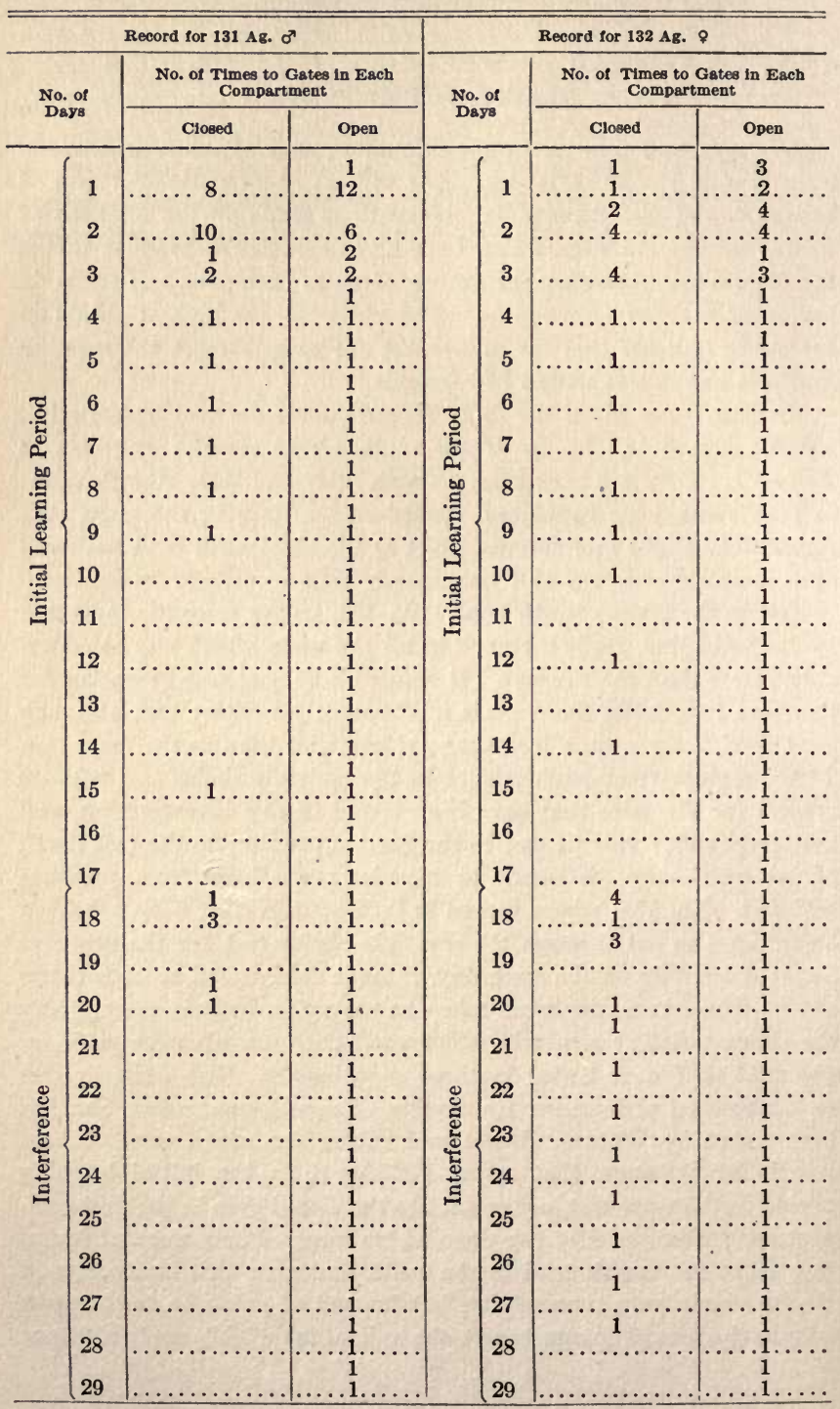




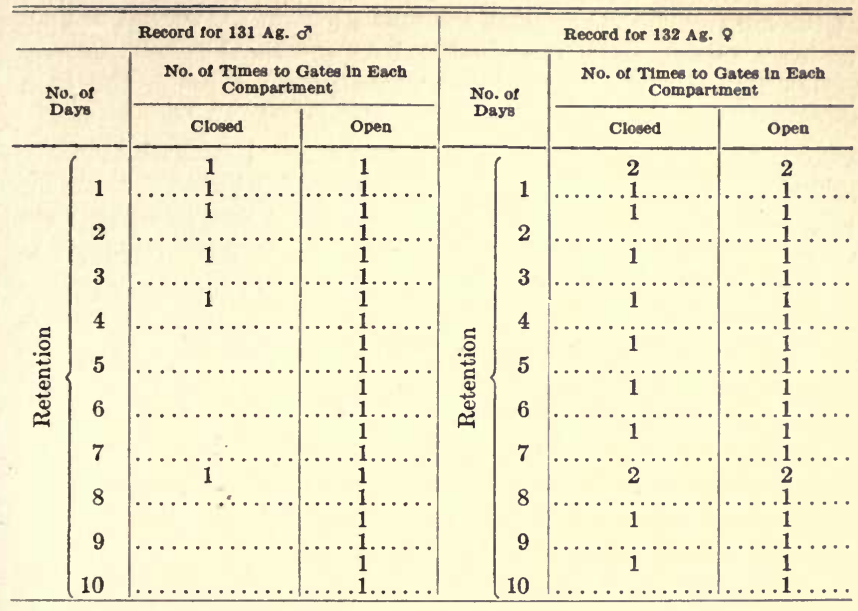

by first going to the closed gate in the second compartment before completing the day's record. After the position of the open gate had been changed, from the right to the left in this case, at the interference point, i.e., the eighteenth day, the mouse tried to pass through the previously open gates, but from the third day after the interference had been given a new rhythm was set up, which lasted until the last trial, where a perfect record of no errors was made. The rhythm in this case reversed the previous rhythm by the mouse trying to pass through the closed gate in the first compartment, but failing to pass this gate it quickly ran around to the successful gate and dashing through, continued on to the open gate in the second compartment. As will be shown in an accompanying table, it is interesting to note that this mouse, except for the first three days of training and the first two interference days, made only a single error on any one day. In Table $\mathrm{X}$. are given the daily error records for the same two mice, Nos. 131 and 132, that were made in the maze test. The left half of the table gives the complete record for No. 131, while at the right is given the record of No. 132. The first column gives the number of days and indicates the extent of each learning period; the second column, the number of times that each mouse tried to pass through the closed gates in each compartment (if two numbers are given for any one day the upper number represents the errors in the first compartment and the lower one errors in the second compartment); while the third column gives the number of trials made 
at the open gates. The errors are thus given in the second column for each mouse, while the number 1 in the third column merely means that the animal has successfully passed through the open " 1 "

gates. The record indicated in the table by: 11 and found to occur on the fourth day for both mice, is repeated several times for each animal. This rhythm may be interpreted by saying that the animal successfully passed the first open gate, without making any errors in the first compartment, but ran around to the closed gate in the second compartment and was thus credited with an error before it finished the day's record. By a glance at the table it will be seen that the single error that was made in the second compartment was not eliminated until the tenth day for mouse No. 131, and one day later No. 132 made a perfect record. This same error occurred once more on the fifteenth day for No. 131, and of the twelfth and fourteenth day for No. 132. These examples are typical in that they show that errors in an animal's behavior are not suddenly discontinued, but are gradually eliminated. Further, it may be noted that after only two days of the interference test, the eighteenth and the twentieth, No. 131 changed its entire movement habit; after only six errors it was able to make the eorrect turn to the left in each compartment, while before the interference was set the correct turn had been to the right. This record shows a rather unusual amount of flexibility of behavior; only a few animals have been observed to make a similar record. In fact, if such records were found to be common in animal behavior we would have to alter our conception of a kinesthetic, or muscle sense movement; for the quick readjustment as exemplified in the behavior of mouse No. 131 would hardly be eompatible with our idea of such a sense. The observations of the writer lead him to believe that kinesthesis was the all important element in adjusting the movements of the animals that were observed in this investigation. It is also to be remembered that in the case of No. 131 any visual, olfactory or gustatory clews, if they existed as such for the animal, were so left under the experimental conditions, that they would favor the production of errors during the interference period and not tend to their elimination. The behavior of mouse No. 132 in the interference period, with numerous errors, appears to be the more general type of animal reaction.

Turning again to the subject of the fixed rhythmic type of behavior it may be seen in Table X. that, in the case of No. 132 , the " 1 ",

record which is indicated by 1 in the initial learning period, 
"1 1",

changed to 1 in the interference test, and this particular performance persisted nearly a month later in the retention period.

It has been noted from the careful study of each animal's behavior, that individual errors, or tendencies to make such errors, are, as a rule, gradually overcome, that a wrong movement made in the first few trials persists throughout several succeeding trials in a gradually diminishing extent. One mouse persisted in turning once to the left gate in the first compartment, when the gates were opened on the right side. It continued to do this for several days, when it was noted that it began to go only part way to the left gate; then turning around it took the successful path. This mouse never completely broke the habit, but in the end, the turn to the left had degenerated into a quick whirl around in a circle, followed by a dash through the proper gates. This type of behavior has been noted by other observers; the following is quoted from page 32 of Basset's monograph: "As in the maze experiment, many of the inbred rats were subject to errors which persisted throughout the experiment. In particular may be mentioned one rat that invariably formed a loop in the course from the entrance to the point of operation."

Fig. 7 gives the daily record for mouse No. 134, Agouti $q$, whose average time records are given in Table VI. This record shows an initial set of seventeen trials in the maze test that almost duplicates the theoretical learning curve. The daily record for eight days, from the tenth trial to the eighteenth, which marked the application of the interference test, shows that the animal approximated the physiological limit of performance; taking an average time of one second per trial and making no errors at all during that period. The interference effect for the animal is slight, as shown by the first group of two trials, the remaining ten trials of the interference are a little irregular, but the noticeable individual difference in the behavior of this mouse is to be seen from the very poor record it made in the multiple choice test. It did not make a successful trip in that test until the sixth day and then failed for eleven consecutive days, from the eighth to the eighteenth day, inclusive, and also failed on the twenty-second day. During all these trials the animal appeared to be in very good health, it was active in the apparatus as well as in its nest box and made plenty of errors in testing the colored doors. It is tempting to speculate that the poor records of this mouse in the multiple choice test were due to an interference effect carried over from the previous training in the maze, but perhaps the relatively poor retention test that followed would seem to disprove 
this assumption. This ease indicates that an experimenter can predict the actions of an animal to only a limited degree, for, after making consistantly good records in any one task, some external or internal factors, unknown to the investigator, may become operative and break up the expected sequence of learning. It also emphasizes the importance of testing an animal in more than one task before we finally grade its behavior.

If space permitted it would be interesting to give in detail the learning curves of mice that illustrate still other kinds of individual differences. It may be well to call attention to the average records of mouse No. 147 (see Table III.), that failed completely to make a successful trip through the maze, although it was tried in every one of the tests. It finally succeeded in making the poor average record of 159 seconds in the multiple choice test, but when retested at the time the retention test was given to the other mice, it again failed completely in the maze test. Because of the great amount of individual differences among the animals, it is difficult to find the record of a single mouse that made a record that was similar to the average for each task. Only No. 133, whose averages are given in Table VI., and No. 189, in Table III., approximated an "average" record. The record of No. 142, in Table III., is interesting in that it shows consistently uniform performance throughout all the tasks. This mouse made the following averages: 36 seconds in the initial learning period, 24 seconds for the first two interference trials, 36 seconds for the last ten interference trials, 35 seconds for the multiple choice test, and 33 seconds for the retention test. Another type of animal behavior is to be seen in the case of mice that made very poor records in the initial maze tests, and good records in the multiple choice and retention tests. ${ }^{14}$

The multiple choice test, which did not favor the production of a stereotyped form of reaction, nevertheless showed some interesting types of individual and group responses. It was found that the animals exhibited three types of behavior, which were not definite, but merged one into the other, so that an animal might use one of them on a certain day and another type on the next. The types of reactions were as follows:

Type 1.-Response by slowly and carefully "examining," visually or otherwise, each of the colored doors, very suddenly becoming oriented and dashing through the successful red gate.

Type 2.-The animal would react by trying the gates in a definite

14 See records of the following mice in Table III., Nos. 138, 153, 154, 165, 171, 178, 181, 187, 188, 206, 207, 209, 210, 211, 212, and in Table IV., No. 169. 
order, from right to left, or left to right, but going through the unlocked door as soon as it was reached.

Type 3.-Responding by trying the gates once each, in an irregular manner, and finally going through the right gate apparently by chance.

It was noted that the majority of the animals that were observed in this investigation used types 2 and 3 interchangeably. A few animals used type 1 for several days in succession and appeared to actually discriminate before they made their final choice of the gates. This type 1 reaction was noted by Burtt in his experiments entitled, "A Study of the Behavior of the White Rat by the Multiple Choice Method."15 In the case of one rat he says: "In problem 1 she would at times become oriented very suddenly, dash to the right end and then across to the correct door." Types 2 and 3 of this investigation correspond to the $B$ and $C$ types found by Hamilton in the study of primates and rodents. ${ }^{2}$

15 Harold C. Burrt, "A Study of the Behavior of the White Rat by the Multiple Choice Method,' Journal of Animal Behavior, May, 1916, Vol. 6, No. 3. 


\section{HEALTH CONDITIONS AND LEARNING ABILITY}

IT is generally conceded that bodily changes in the general health of an animal may greatly tend to interfere with the formation of habits. This investigation, however, has shown that a number of ani-

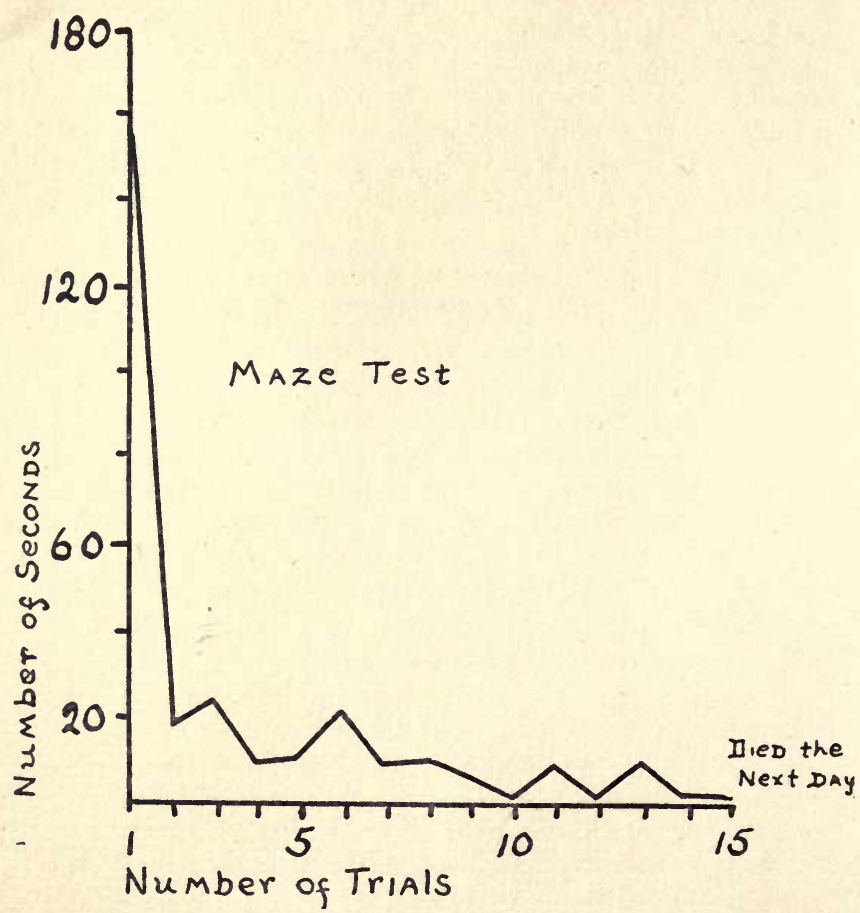

Fig. 9. Daily Record Curve for 156, White o, that gave good records although stunted and very ill throughout all the test.

mals have made exceedingly good records although they were apparently in very poor health. They were put through the tests, more out of curiosity to see what they would do than for anything else, and the experimenter was surprised to find them making very good 
records up to the very day they died. An example of such a case is shown in Fig. 9, which gives the daily record of No. 156, White $\sigma^{2}$, who although stunted and very ill throughout the experiment, nevertheless made good records. This mouse did not seem to eare for the reward, which was the food to be found at the end of a successful trip, and when it returned to its next box it suddenly became very inactive, and did not appear to arouse itself again until it was tested the following day. The tables also indicate the incomplete records of several mice that made good records up to the time of their death, and show that when a habit is once firmly fixed it may resist a good deal of distracting influences. 


\section{FAMILY HISTORIES}

We may now take up in detail the family histories. Fig. 10 gives a graphic representation of matings, from which were selected two mice, No. $20 \mathrm{Y} \delta$ and No. $26 \mathrm{Y}$ \%, that made the unusually poor records of 115 and 183 seconds respectively, though the other mice in the same litters had good records. The parentage of Nos. 20 and 26 was unknown; they were mated and gave two litters, each composed of three males and one female. Three mice in these two litters gave unusually slow records and made considerably more errors than normal. Two other mice gave poor records; two gave good records, while one died before it was tested. It is unfortunate that both females in these litters died before further offspring could be obtained. Table 1 gives the complete record of both time and error averages for these mice. It is a question whether or not selection of parents having poor records tended to produce more than the normal number of offspring slow to learn. Further investigation ean alone afford an answer.

The mice whose records are given in Tables II. and III. are graphically represented in Figs. 11 to 14 inclusive. They have been carried down to the eighth generation and are still being tested. These animals are related and compose a group which is here called the white family. The matings began from an original pair of albino mice that were purchased from a dealer in the spring of 1913 . The records for the parents and the first six generations are given in Fig. III., and it is to be noted that the time averages for the animals, whose eatalogue numbers are lower than 128 , are based upon performance only in the initial learning period in the maze test. The time records for all the animals of the $\mathrm{F}^{7}$ and $\mathrm{F}^{8}$ generations, and one family, Nos. 135 to 138 in the $F^{6}$ of Fig. 12, are based on an average performance in all the tests as previously explained. ${ }^{16}$ The parents of the white family, Nos. 8 and 9, were quick to learn, making averages of thirteen and eighteen seconds respectively. The first generation was composed of four mice, one was not tested, two took considerably longer to learn the test than either of the parents, while the remaining animal made a quick record. The family average equalled $59.7 \pm$ P.E. 15.7 seconds. A successful mating was ob-

16 The average time for the 71 mice that was calculated upon performance in all tasks was $55.9 \pm$ P.E. 3.5 sec., and this was practically identical with the average time made by the 183 mice that was based on the records for only the initial learning period of the maze test; namely, $54.1 \pm$ P.E. $2.3 \mathrm{sec}$. 

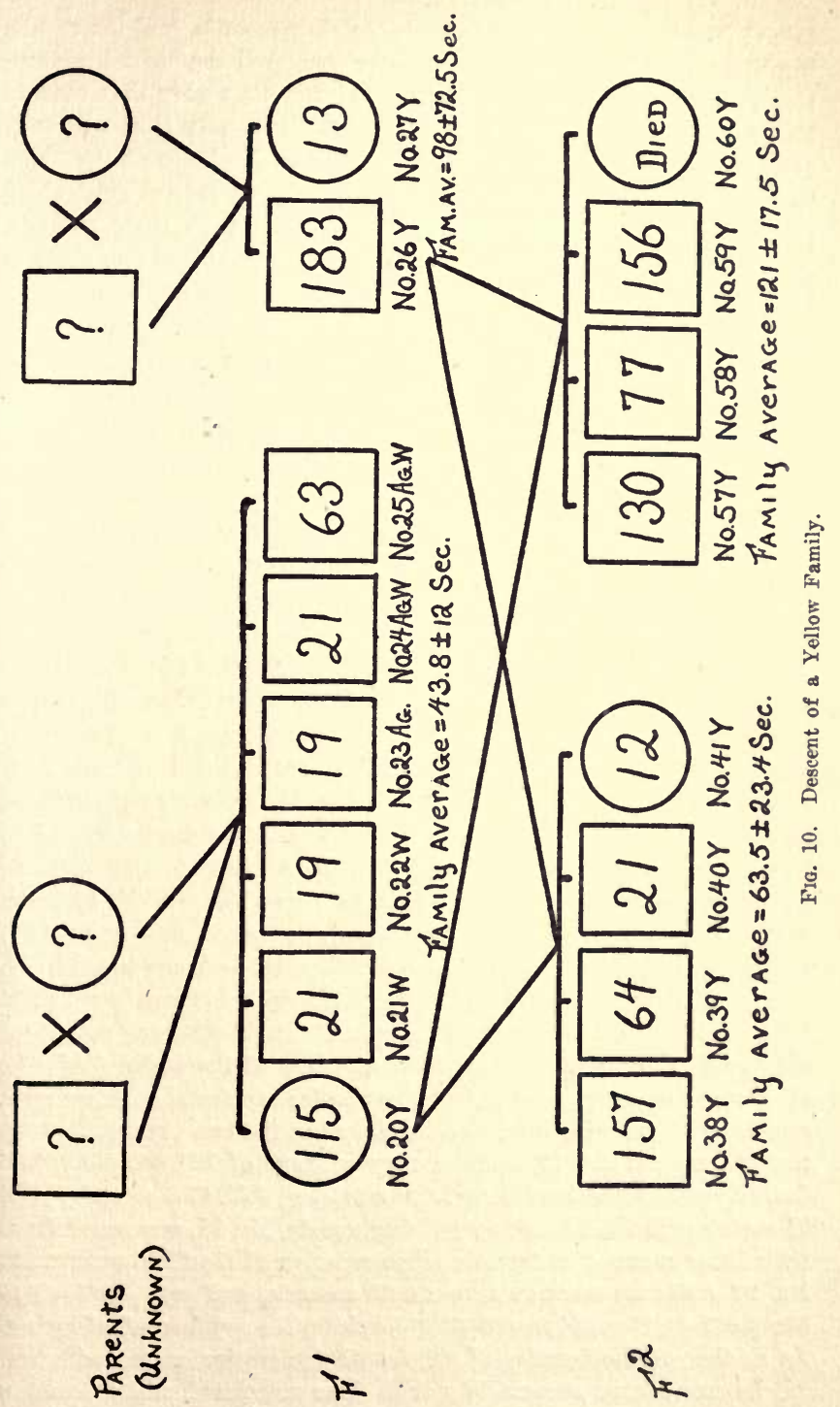
tained from the two mice that made the slow records, and the resulting litter of five females and one male composed the second generation of the white family. All the mice of this litter gave time records that were better than the average, so that the family time was very good, amounting to $23.3 \pm$ P.E. 5.6 seconds. A glance at the chart will show that the majority of the mice of this second generation tended to resemble their grandparents rather than their parents. No. 48 , the male of the litter, was quick to learn and made an average time of ten seconds. He mated with two of the females of the same litter, namely, No. 50, that made an average of 20 seconds, and No. 51, with an average of 9 seconds. From these two matings two litters were obtained that compose the third generation of the strain. All the mice in these litters made poorer records than either of their parents, and thus reversed the condition that occurred between first generation parents and second generation offspring, that we have just examined. The offspring of No. $48 \times$ No. 50 were two females and one male. The male, No. 66, made the very poor average of 113 seconds, while one female took 35 seconds, and the other 75 seconds. Four offspring of this generation, three males and one female, resulted from the mating of No. $48 \times$ No. 51 , while here again one of the males, No. 78, made the poor record of 122 seconds, one other male, No. 77, took 68 seconds, and the female, No. 76 , made an average of 31 seconds. The remaining male died before it could be tested. It will thus be seen that from the mating of No. 48 with two females, two litters were obtained that gave almost identical family averages; the average for Nos. 65,66 , and 67 was $74.3 \pm$ P.E. 15.9 seconds, while the average for Nos. 76,77 , and 78 was $73.7 \pm$ P.E. 19.5 seconds. The only litter that was successfully raised to continue the fourth generation of the strain was obtained by back crossing No. 66 , who made the poor average of 113 seconds, with his own parent No. 50 , with the quick average of 20 seconds. Their offspring composed a litter of two males and two females. One of the males died; the other made an average record of 53 seconds; one female made a good record of 24 seconds; while here again, as in the two previous litters, a single mouse, No. 72, made a poor average of 121 seconds. The family average for these three mice was $66 \pm$ P.E. 22.3 seconds. No. 71 mated with No. 72, but only a single male, No. 91, was saved from their litter to stand as the sole representative of the fifth generation. No. 91 made an average time of 38 seconds, and was destined to become the paternal parent of a considerable number of offspring. As neither of the females of the fourth generation mated with No. 91 , he was mated successfully with four unrelated white females, 


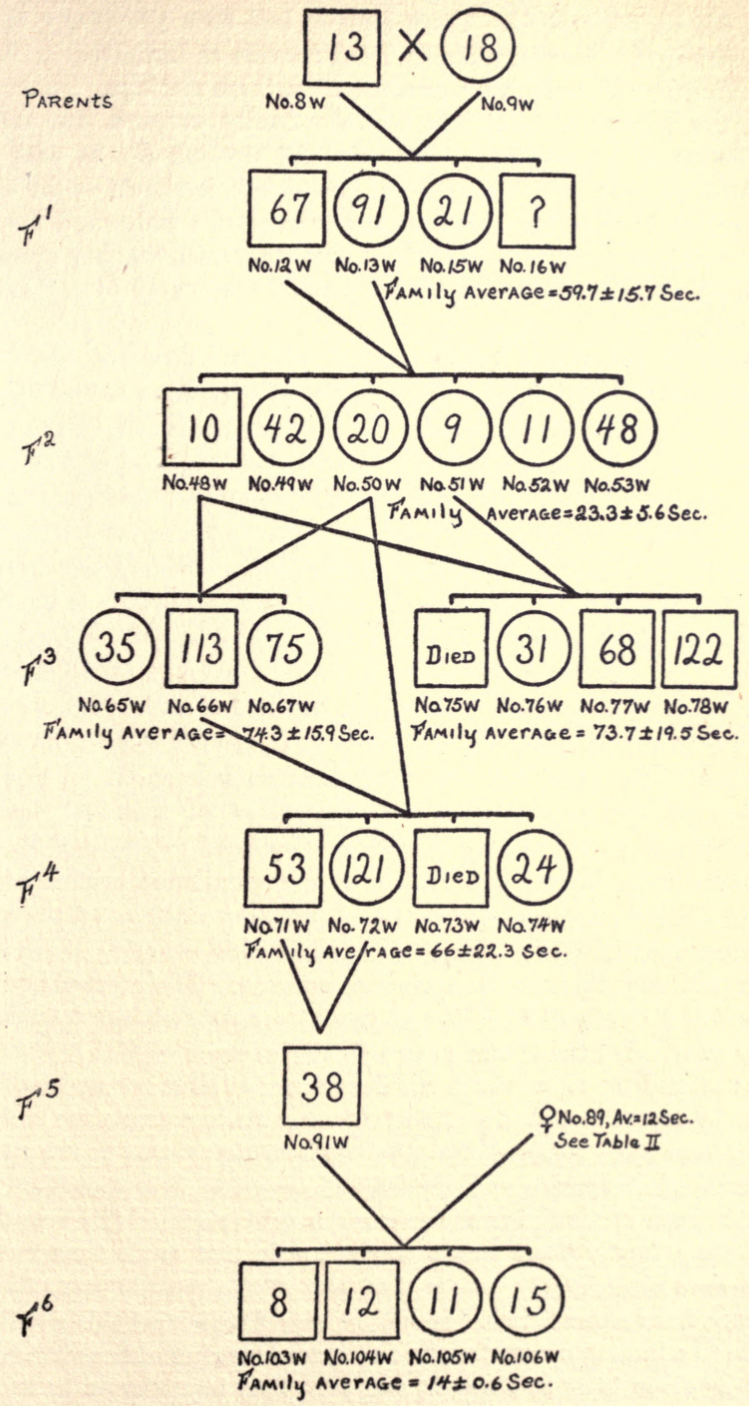

Fig. 11. Descent of a White Family. 
Nos. $86,87,88$, and 89 . These females had been previously tested and found to give exceptionally good records as indicated in Table II. Twenty-seven offspring resulted from these matings. Their records are remarkably uniform and the family averages are among the lowest so far obtained. The result of erossing No. 91 with No. 89 , who made the quick average of 12 seconds, is shown as the sixth generation in Fig. 14, which is composed of two males and two females. These mice were uniformly quick to learn, making averages of $8,12,11$ and 15 seconds, with a family average of $14 \pm$ P.E. 0.6 seconds.

Fig. 12 represents a continuation of the history of the white family resulting from the mating of No. 91 with No. 87, that made a good time record of 15 seconds. These mice produced, in the sixth generation, two litters, the first of which was composed of five males and two females that made exceptionally quick and uniform records, and showed, as in the previous mating that we have just discussed, a considerable amount of family resemblance. Their family average amounted to 13.1 seconds with the low P.E. of 1.7. It is to be noted that three of the mice of this litter made an average of eight seconds, two an average of twelve seconds, one an average of 16 seconds, and another 28 seconds. The second litter of No. $91 \times$ No. 87 gave two males and two females, and again good records were made by all but one of the mice, No. 138, that made an average of 76 seconds. The other mice gave average time records of 23,9 and 11 seconds respectively, while the family average amounted to $29.7 \pm$ P.E. 11.4 seconds. The seventh generation of this particular branch of the white family was composed of three different matings of the sixth generation mice. No. 115, with an average of 12 seconds, was crossed with No. 118 that made a similar average. Their offspring are shown at the left of Fig. 15, and two litters were obtained from the same mice. The first litter gave a family average of $41.1 \pm$ P.E. 7.5 seconds, and the members of this family made fairly low and uniform records, except in the case of No. 143, that made a poor time average of 100 seconds. Four of the other mice made records in the neighborhood of 30 seconds and one took 16 seconds. It is a curious fact that in each of the litters of the seventh generation of this branch of the white family there was a single female that made time records that were considerably poorer than any of the records made by the males of the same litters. It will be also found that this conditior. holds to a limited extent for the two other branches of the strain that will be given later in Figs. 13 and 14. This irregularity in the behavior of the females tended to increase the mean variations for the 


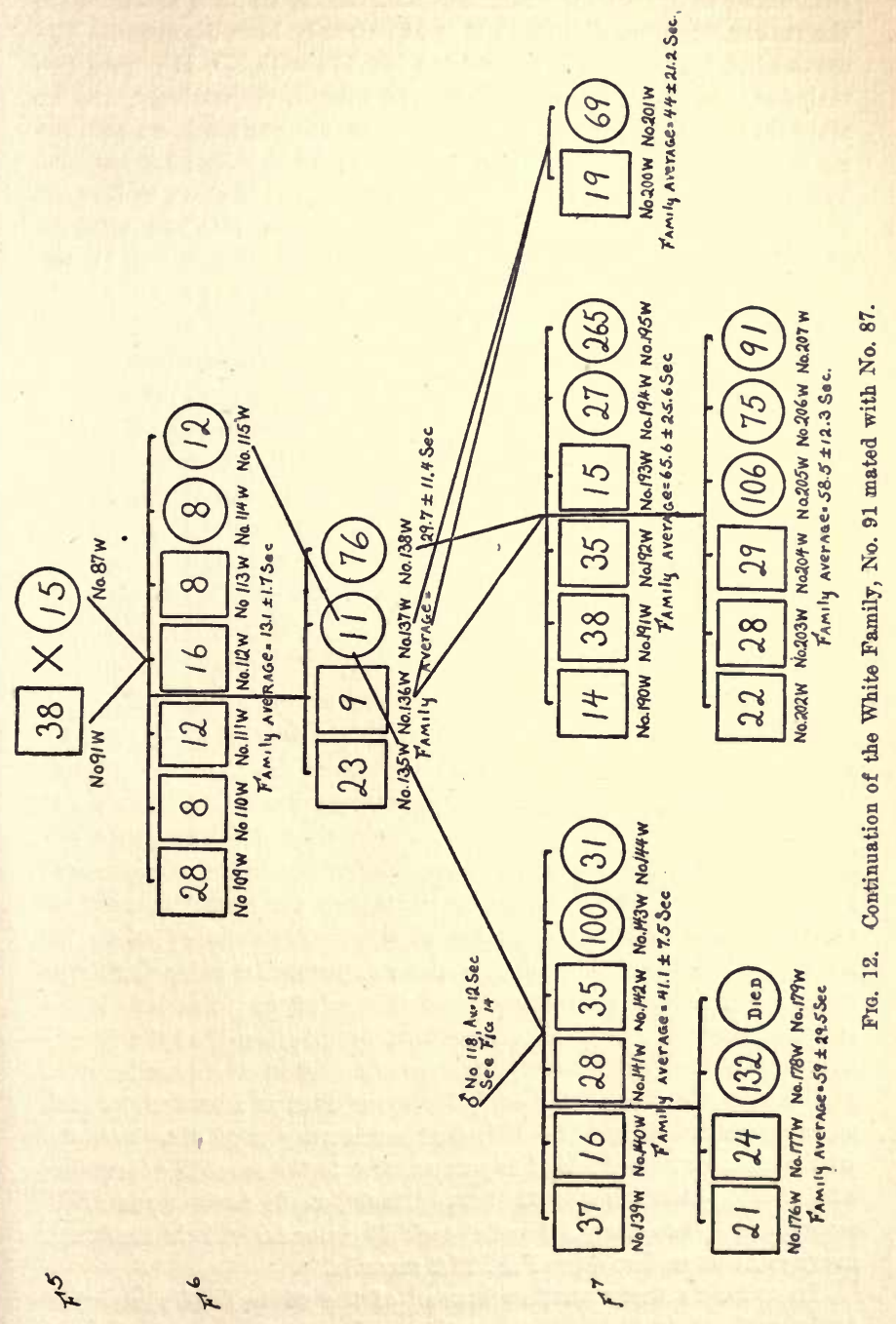


litters and to decrease the family resemblances, while it accounts for the rather large sex difference that has already been discussed. The second litter, resulting from crossing No. 115 with No. 118, gave two males that made averages of 21 and 24 seconds respectively, one female that died, and again a very slow female that made an average of 132 seconds. The family average was $59 \pm$ P.E. 29.5 seconds. The middle group of seventh generation mice that is given in Fig. 12, resulted from two successful matings of a male, No. 136, with an average record of 9 seconds, with No. 138 whose average was 76 seconds. It may be seen that in the first litter, Nos. 190 to 195 inclusive, all the males and one female made good records, while again, as was found in the previous litters of this generation, one female made exceptionally poor records. This was the case of No. 195 that made an average of 265 seconds. The family average amounted to $65 \pm$ P.E. 25.6 seconds. The litter that was subsequently obtained from the same parents gave three males that made good records, 22,28 and 29 seconds, respectively, and three females that made time averages considerably slower than the average for the entire population. One female made an average of 75 seconds, another 91 seconds, and still another 106 seconds. Again it may be noted that the females fell behind the males in quickness of learning. The family average of the second litter is similar to the first, and amounted to $58.5 \pm$ P.E. 12.3 seconds. It is hoped that sufficient data may be later obtained to show whether or not there is a closer resemblance between litters belonging to the same parents than between unrelated litters, and also to determine whether or not mice belonging to the first litters of any two young parents tend to be superior or not to the mice that are produced from these same parents when they are considerably older and have produced several litters of mice. The number of double litters that has been obtained in these experiments is hardly large enough to warrant any conclusion on this point, but it may be noted that several of the eases that have been found show that the family averages of first and second litters overlap when due consideration is given to the size of the probable error that is attached to each average. No. 136 and No. 137, that made very good time records, were mated, and they added two more mice to the seventh generation of the white family; one of them, a male, made' an average of 19 seconds and the other, a female, took 59 seconds. Their combined average amounted to $44 \pm$ P.E. 21.2 seconds.

In order to study another branch of the white family we must again go back to the fifth generation and note what resulted from mating No. 91 with another white female, namely No. 86, that also 
made a quick time record of $\mathbf{1 5}$ seconds. The records for this branch of the strain are given in Fig. 13. As in the other branch we have just discussed, No. 91 again produced an exceptionally quick and uniform family in the sixth generation. This litter was composed of three males and three females, Nos. 122 to 127 inclusive. Four in the litter made time averages of fifteen seconds or lower, while the other two took 32 and 33 seconds each. Their family average amounted to $19.1 \pm$ P.E. 3.4 seconds. No. 125, with an average of 9

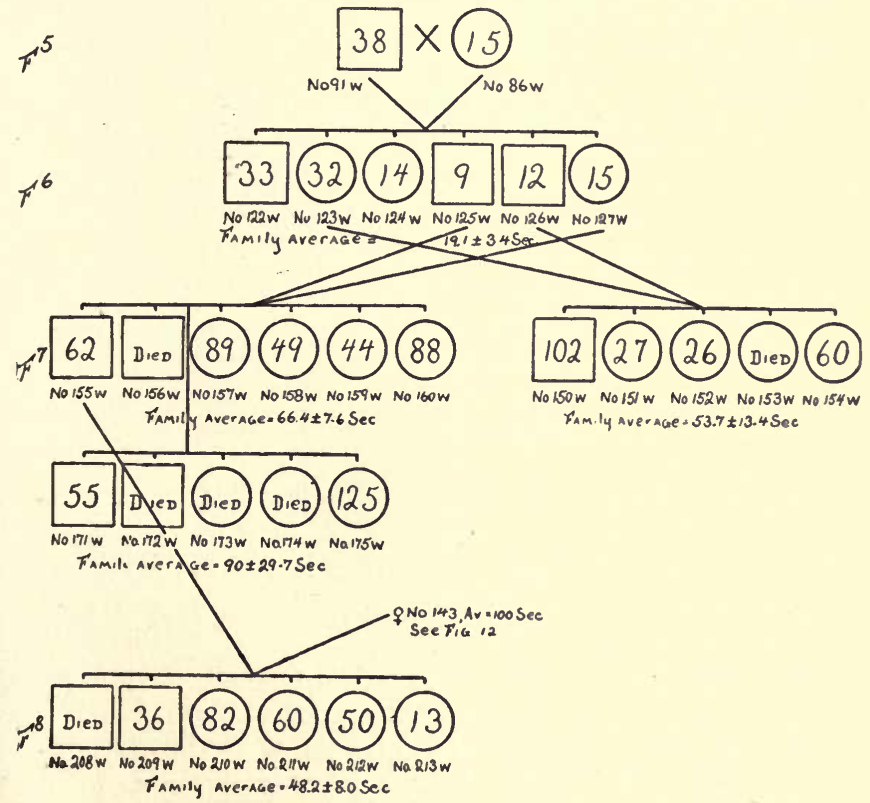

Fig. 13. Continuation of the White Family, No. 91 mated with No. 86.

seconds, and No. 127, whose average was 15 seconds, were mated and they produced in the seventh generation two litters. The first was composed of six mice, Nos. 155 to 160 inclusive; two were males and four females. All these mice made averages slower than any of their sixth generation kin. One male made an average of 62 seconds, two females gave average records of about 90 seconds, one of 44 seconds and another of 49 seconds. The family average here was fairly high, amounting to $66.4 \pm$ P.E. 7.6 seconds. The second litter was composed of two males and three females, but Nos. 172 and 173 died be- 
fore they could be tested, while No. 174 did not complete its record. The incompleted records of this mouse are given in Table III. The one male that lived, No. 171, gave an average of 55 seconds and the female made an average of 125 seconds. Their combined average equalled $90 \pm$ P.E. 29.7 seconds. Once again it may be noted that the female was the one that made the comparatively poor time record. The other litter of the seventh generation was obtained from mating No. 123 , whose average was 32 seconds, with No. 126, whose average was 12 seconds. Their offspring, Nos. 150 to 154 inclusive, compose a litter of one male and four females, one mouse, No. 153, did not quite complete its record (see Table III.). The male of this litter, No. 150, made a poor average record of 102 seconds, and it is worth calling attention to the fact that its case is the only one, among all the sixth, seventh, or eighth generations, where a male has made a very poor record. Two females, Nos. 151 and 152, made good records of 26 and 27 seconds each, while the remaining female made an average of 60 seconds. The family average in this case was $53.7 \pm$ P.E. 13.4 seconds. The matings for the eighth generation have only just been started; one litter, however, Nos. 208, to 213 inclusive, has been obtained by crossing No. 155, a male, with a time average of 62 seconds, with No. 143, whose average was 100 seconds. Their offspring were six in number, two males and four females. One male, No. 208, died, but its incomplete records are given in Table III., and the remaining male, No. 209, made an average record of 36 seconds. One female, No. 213, gave a good average of 13 seconds, while the other three females ranged from 50 to 82 seconds. The average family record amounted to $48.2 \pm$ P.E. 8.0 seconds.

The fourth and last branch of the white family is given in Fig. 14. Here it may be seen that No. 91 was mated with another female, No. 88 , that made the very quick average record of 9 seconds. The sixth generation litter of four males and two females that was obtained from this mating made the best family record that has so far been obtained, namely, $12 \pm$ P.E. 1.0 second. None of the mice made an average time record exceeding 20 seconds. It is an interesting point that all but one of the 27 offspring of No. 91 made time records considerably superior to the average. Three matings were made from these sixth generation mice. No. 116, a male, was erossed with No. 121, and these two mice made average records of 10 and 12 seconds respectively. Two seventh generation litters were obtained from them. The first litter, Nos. 161 to 166 inclusive, was composed of three males and three females, with a family average of $34.3 \pm$ P.E. 7.4 seconds. Two of the males made good records of 14 


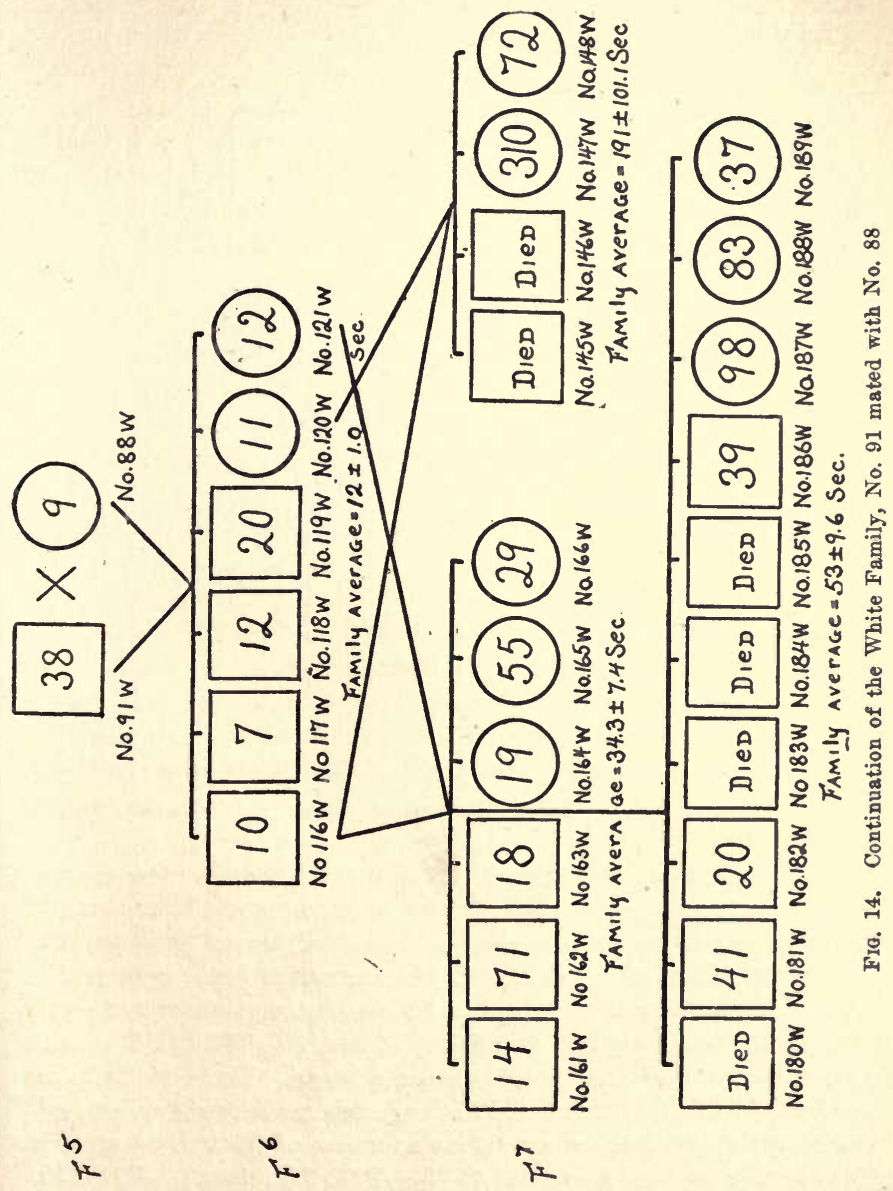




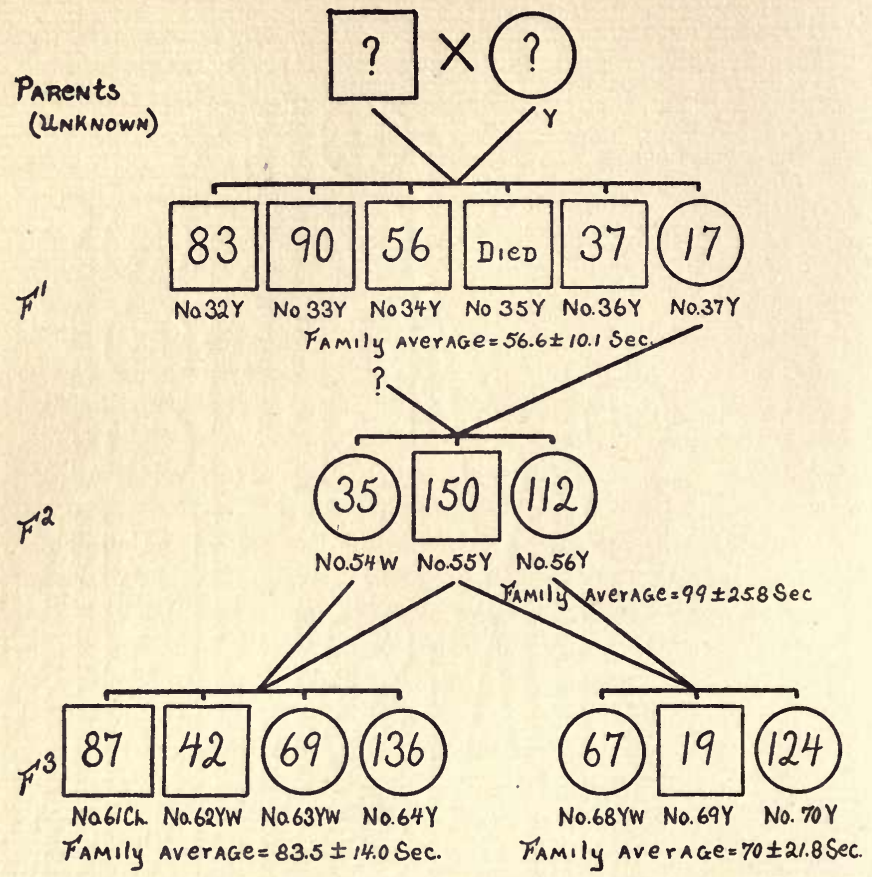

Fie 15. Descent of a Family of Mice consisting mostly of Yellow Individuals.

and 18 seconds, while one gave a record of 71 seconds; two females also made good records, and one an average record. None of the mice in this litter made records as low as either of their parents. The second litter of No. $116 \times$ No. 121 was rather large, composed of ten mice, but three of the seven males died before their records were completed (see Table III. for records of Nos. 180, 183 and 185), and one male, No. 184, died before the tests began. Three of the males and one female that completed their records made fairly quick averages, while two females gave time averages of 98 and 83 seconds. The family average amounted to $53 \pm$ P.E. 9.6 seconds. When No. 116 was mated with No. 120, whose average was 11 seconds, a sixth generation litter of four mice resulted; two were males and died before their records were completed (see Table III. for records of 145 and 146), and one female, No. 147, gave the very poor record of 210 seconds. This was the female that failed completely in all the maze 
tests, while the other female, No. 148, made a poor record of 72 seconds. It is to be noted again that in the seventh generation of this branch of the white family, four of the females made time records inferior to any of those made by the males of the same generation.

Another family, mostly of yellow mice, was derived from a yellow female and an unknown male, probably white. The first generation from this mating gave a litter of six, Nos. 32 to 37 inclusive. The records of five of these, one having died, are given in Table IV. and are graphically represented in Fig. 15 . This litter gave a family average of $56.6 \pm$ P.E. 10.1 seconds. Two of the males, Nos. 32 and 33 , made poor records; No. 34, an average record of 56 seconds; while the remaining male made a fairly good record of 37 seconds. No. 37, the only female of this litter, gave a record of 17 seconds; she mated but once, and it is not known with which brother. She bore in the second generation two females and a male, Nos. 54, 55 and 56. One female, No. 54, made a record of 35 seconds, while the other female made a poor record of 112 seconds. The male, No. 55, also did poorly with an average of 150 seconds. No. 54 and No. 56

PARENTS
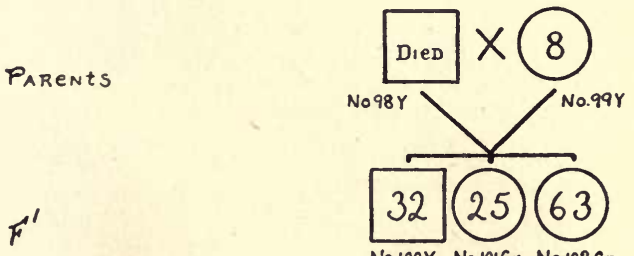

No.100Y Na.101Gr. No.102Gr.

Amily average $=40 \pm / 9.0 \mathrm{Sec}$.

$F^{2}$

$1^{2}$

$f^{3}$

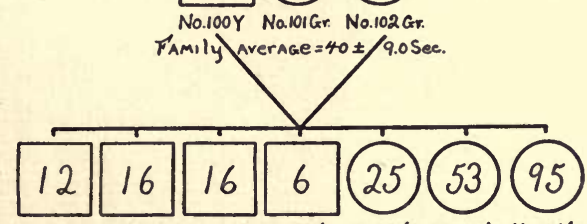

Na.128AGE No.129AG. No.130AG. Na/31 AG. Na/32AG. Na.133AG. No.134AG.

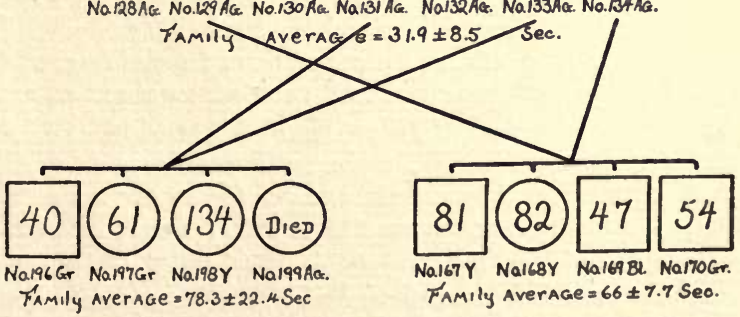

FIG. 16. Descent of a Family of Mice composed of Colored Individuals. 
were both crossed with No. 55 , and two litters resulted. No. $55 \times$ No. 56 gave Nos. 68,69 and 70 in the third generation, and No. $55 \times$ No. 54 gave Nos. 61 to 64 inclusive. From a survey of the complete records of these mice, it is seen that although the second and third generations came from the female, No. 37 , which made the exceptionally low record of 17 , still, two of her young in the second generation made poor records, and Nos. 61,65 and 70 in the following generation did the same.

The last family history that will here be discussed is composed of another strain of colored mice that began from a mating of two yellow mice. The records for these individuals are given in Table VI. and are graphically represented in Fig. 16. This family was started in order to see whether there was any real correlation between strains of colored mice and their ability to learn quickly and to adapt themselves to varied conditions. It was especially desired to test the learning ability of a greater number of yellow mice, and to this purpose the two founders of the family, Nos. 98 and 99 , were both yellow mice that came from the same yellow strain that had previously exhibited individuals that were very slow to learn. It was also desired that a further study of the effects of close inbreeding be carried on independently of the other problem, and for this purpose certain strains of the family are now being bred with this object in view. The inbreeding in this investigation has not been carried on close enough, or for a sufficient number of generations, to give any definite results. It is to be noted that in the white family it was necessary to outbreed in the fifth generation. To return to the records of the family of colored mice, No. 99 , of the parent generation, made a very good record of eight seconds, while the male died before he was tested. The first generation from this mating gave one yellow male and two gray females. The male and one of the females made good records, while the other female gave an average time of 63 seconds. The family average was $40 \pm$ P.E. 9.0 seconds. The male of this generation and the normal female, No. 102, were mated and a litter of four males and three females resulted that composed the second generation. All these mice were of an agouti color in which a good deal of yellow pigment was added. All the males and one female, No. 132, made good records; a female, No. 133, made an average of 53 seconds, and No. 134 an average of 95 seconds. Here the family average was $31.9 \pm$ P.E. 8.5 seconds. Two matings were obtained from the mice of this litter, and the resulting offspring compose the third generation; No. 131, with a very good average of 6 seconds, was mated with No. 133, with an average of 53 , and gave 
Nos. 196 to 199 inclusive; while No. 129 , average $16, \times$ No. 134 , average 95, gave mice Nos. 167 to 170 inclusive. The litter of No. $131 \times$ No. 133 was composed of a gray male, with an average of 40 seconds; a gray female, with an average of 61 seconds; a yellow female that made the very poor record of 134 seconds, and one agouti female, No. 199, that died before its records were completed. This agouti female, however, made very good records in the initial learning, and both interference periods of the maze test before it died. Its records may be considered similar to those of No. 156, already discussed (see Fig. 12). The family average for the first litter in the third generation was $78 \pm$ P.E. 22.4 seconds. The second litter in this generation was composed of Nos. 167 to 170 inclusive; offspring of No. $129 \times$ No. 134. The family consisted of three males and one female; there was a yellow male and a yellow female, a gray male, and finally a black mouse also a male. The two yellow individuals, Nos. 167 and 168, made the poor averages of 81 and 82 seconds respectively; the black colored male took 47 seconds, while the gray male 54 seconds. Their family average was $66 \pm$ P.E. 7.7 seconds. This experiment has not extended far enough to give as yet any definite results, but it is interesting to note, that, 'as was found in the case of the white mice, the males continue to make, on the whole, better average records than the females, and the three yellow mice, Nos. 198, 167 and 168, in the third generation make the poorest time records in their respective litters. If there is a tendency for the yellow mice to be slow to learn, this point can only be finally determined as the work of this investigation continues. 


\section{SUMMARY}

1. Albino and colored mice can be used to advantage for laboratory work in animal behavior.

2. Both the maze and the multiple choice apparatus that were used in this investigation appear well adapted for this kind of work.

3. There is a marked difference in individual behavior, with a close correlation between time and error records.

4. There appears to be a fairly close relation, in the maze test of this investigation, between performance at the beginning of the initial learning period with performance at the end of the same period. The quick learners appear to make the best records at the end of the test. This relation appears to hold for the results in the multiple choice test, but in this case the coefficient of correlation is much lower.

5. There appears to be practically no correlation between performance in the maze test with performance in the multiple choice test, and this may be due to factors peculiar to each test, as has already been discussed in the body of this thesis.

6. On the whole, the animals that do well in the initial learning period of the maze test continue to make good time averages in both of the interference tests and in the retention test.

7. The quick learners appear to exhibit a considerable amount of flexibility of behavior.

8. Definite types of movements were noted in the formation of habits in both the position test and the discrimination test.

9. There appears to be a certain amount of interference effect carried over from one type of reaction to another.

10. Poor health in an animal may not necessarily be correlated with slow learning ability, for when a habit is once fixed it may resist a considerable amount of disturbing influence.

11. There appears to be no particular resemblance among individuals of the same litter, as judged by their time records for various tests.

12. There appears to be a considerable difference among different strains.

13. There appears to be a sex difference in favor of the males in all the tests of these experiments.

14. The females appear more variable than the males in their behavior. 





\section{CENTRAL UNIVERSITY LIBRARY}

University of California, San Diego

DATE DUE

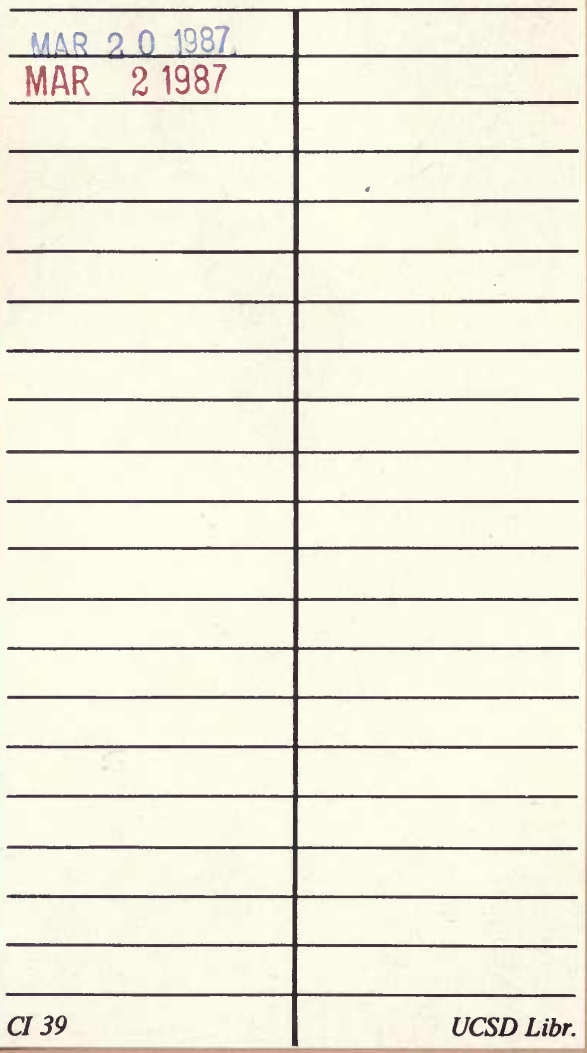


$\therefore ;$ 